University of Nebraska - Lincoln

DigitalCommons@University of Nebraska - Lincoln

$7-2005$

\title{
The July 2003 Dakota Hailswaths: Creation, Characteristics, and Possible Impacts
}

\author{
Matthew D. Parker \\ University of Nebraska-Lincoln, parker@updraft.unl.edu \\ Ian Ratcliffe \\ University of Nebraska-Lincoln, iratcliffe2@unl.edu \\ Geoffrey M. Henebry \\ University of Nebraska-Lincoln, geoffrey.henebry@sdstate.edu
}

Follow this and additional works at: https://digitalcommons.unl.edu/natrespapers

Part of the Natural Resources and Conservation Commons, Natural Resources Management and Policy Commons, and the Other Environmental Sciences Commons

Parker, Matthew D.; Ratcliffe, lan; and Henebry, Geoffrey M., "The July 2003 Dakota Hailswaths: Creation, Characteristics, and Possible Impacts" (2005). Papers in Natural Resources. 1152.

https://digitalcommons.unl.edu/natrespapers/1152

This Article is brought to you for free and open access by the Natural Resources, School of at DigitalCommons@University of Nebraska - Lincoln. It has been accepted for inclusion in Papers in Natural Resources by an authorized administrator of DigitalCommons@University of Nebraska - Lincoln. 


\title{
The July 2003 Dakota Hailswaths: Creation, Characteristics, and Possible Impacts
}

\author{
MATTHEW D. PARKer \\ Department of Geosciences, University of Nebraska at Lincoln, Lincoln, Nebraska \\ Ian C. Ratcliffe and Geoffrey M. Henebry \\ Center for Advanced Land Management Information Technologies, School of Natural Resources, University of Nebraska at Lincoln, \\ Lincoln, Nebraska
}

(Manuscript received 4 February 2004, in final form 15 October 2004)

\begin{abstract}
The authors investigate the meteorology associated with two elongated swaths of crop damage produced by severe hailstorms that crossed North Dakota and South Dakota on 4 July and 20 July 2003. These hailswaths, which were observed in a Moderate Resolution Imaging Spectroradiometer (MODIS) Normalized Difference Vegetation Index (NDVI) image time series, each persisted for more than a month and were associated with local temperature increases, presumably owing to the enhanced Bowen ratio over dry, crop-free ground. This paper documents the creation and evolution of the convective storms that produced the hailswaths, and then presents evidence that devegetated hailswaths may impact future convective weather. Idealized numerical simulations including hailswath-like surface anomalies, as well as analogies to the extant literature, suggest that hailswaths may play a part in initiating new convective clouds, especially when the low-level winds are parallel to their long axes. Analyses of conventional operational observations also show that the 4 July hailswath may have played a part in the initiation and intensification of a convective storm on 17 July and in the temporarily deviant motion of a convective storm that crossed it on 20 July. Because devegetated hailswaths are common to the central and northern plains during the summer months, and because they have heretofore received little study, a deeper understanding of hailswaths' impacts upon moist convection may lead to improved short-term weather prediction.
\end{abstract}

\section{Introduction}

The economic impacts of hailstorms are of great concern to society: Changnon and Hewings (2001) found the average annual cost of hail damage to property and crops to be $\$ 445$ million (in 2001 equivalent dollars). However, the possible longer-term meteorological impacts of hailstorms that devastate croplands (e.g., Fig. 1) have received little attention. On 4 July and 20 July 2003, severe hailstorms crossed the plains of southern North Dakota, northeastern South Dakota, and far western Minnesota, producing long, narrow swaths of crop damage that were detectable using spaceborne sensors. In this paper we investigate the creation of these devegetated hailswaths, review the pertinent literature relating to this phenomenon, and describe the lasting effects that hailswaths may have upon the regional weather. Section 2 presents a brief review of prior work on crop damage by hail, after which section 3 describes the formation and characteristics of the July

Corresponding author address: Dr. Matthew Parker, 214 Bessey Hall, University of Nebraska at Lincoln, Lincoln, NE 68588-0340. E-mail: parker@updraft.unl.edu
2003 hailswaths. The paper then describes the swaths' possible impacts on regional weather. Section 4 investigates local temperature and humidity perturbations associated with the swaths, and section 5 appeals to the literature, to idealized simulations, and to observations in order to address the swaths' possible impacts on future moist convection. Section 6 concludes the paper with a summary and a look at the possible future of research in this area.

\section{Crop-hail damage: A brief review}

We defer to the recent, thorough review on hail and hailstorms by Knight and Knight (2001), and for the sake of brevity we only present aspects of hailstorms that are directly pertinent to the formation of a devegetated hailswath. Notably, the devastating impact of hail upon vegetation is likely to rely not only upon the maximum hail size and hailfall intensity, but also upon the total amount of hail produced (and reaching the ground), and its lateral motion owing to wind (Changnon 1967, 1971; Morgan and Towery 1976; Towery et al. 1976; Sanchez et al. 1996). Frisby (1963) and Changnon (1971) also noted that crop damage by hailstorms depends upon not only the presence of damaging hail but 


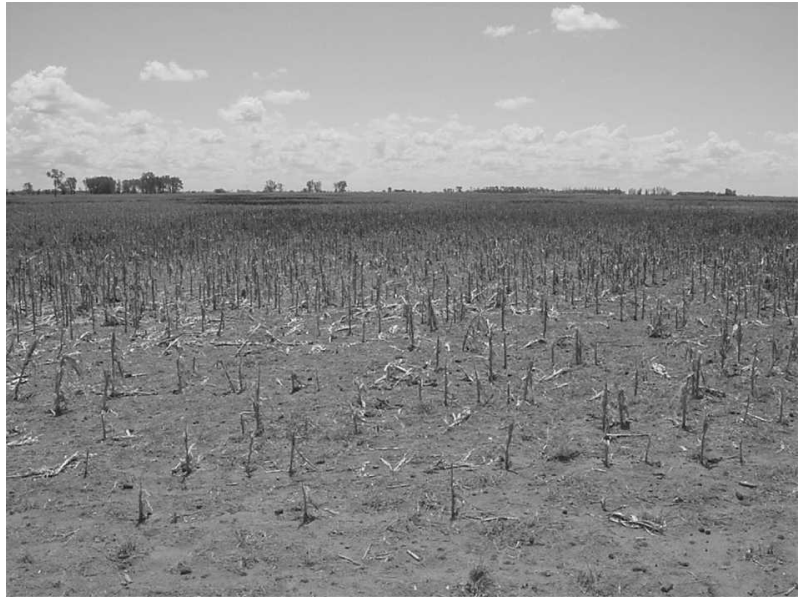

FIG. 1. Damage to a cornfield from the 20 Jul 2004 hailswathproducing storms (discussed in section 3c). Photographed on 20 Jul 2003, 4 miles east and 3 miles south of LaMoure, ND. Photo courtesy of R. Ballinger.

also upon crop sensitivity, which is a complex function of crop type, developmental stage, and the attendant environmental conditions both prior to and following the hail event. Hence, predicting the likely magnitude of crop damage by hail from a given storm is likely to continue as a difficult problem for some time to come.

Frisby $(1962,1963)$ was perhaps the first in the literature to note "swath-type damage patterns" in agricultural hail insurance claims, and found that they were typically $50-200$ miles long $(\approx 80-320 \mathrm{~km})$ and $5-15$ miles wide $(\approx 8-24 \mathrm{~km})$ Frisby $(1963)$ further noted that these swaths were commonly oriented parallel to the upper-tropospheric winds, suggesting that they were from moving storms that produced narrow regions of hail damage. Changnon $(1970,1977)$ elaborated on these structures using mesonetwork and hailpad data, showing that such hailswaths were envelopes of damage within which hailstreaks occurred. Each hailstreak was considered to be the surface outline of a single volume of hail produced by a storm, typically representing a fast-moving, short-lived phenomenon, with an area smaller than $41 \mathrm{~km}^{2}$. Changnon found hailstreaks to be somewhat common, logging 434 over the course of $2 \mathrm{yr}$ within a $1600 \mathrm{mi}^{2}$ area of central Illinois. Hailswaths are fewer and larger, and may comprise many hailstreaks. Such swaths are most often produced by the training of multiple hailstreak-producing storms over an affected area (Changnon 1970), although Changnon and Burroughs (2003) reported on a 585-km-long hailswath produced by one long-lived supercell in the Midwest.

Given their large areas, remote sensing of hailswaths has long been desirable, and Changnon and Barron (1971) showed that aircraft-borne visible and infrared images of fields could be used to discern crop-hail losses. Klimowski et al. (1998) noted that damage from a hailstorm in western South Dakota was visible in Geostationary Operational Environmental Satellite
(GOES) visible imagery, owing to the change in surface albedo caused by the hailfall. This suggests satellite platforms as an ideal tool for observing devegetated hailswaths. Bentley et al. (2002) outlined the basic method used to identify devegetated hailswaths in this study (section 3a), incorporating Normalized Difference Vegetation Index (NDVI) satellite imagery and overlaying severe hail reports from the Storm Prediction Center (SPC). Bentley et al. used the technique to analyze the blow-down of corn as well as the impacts of a subsequent hailstorm and found that hail damage was easier to assess with NDVI imagery than was wind damage, owing to the fact that swaths of damaging hail tended to completely destroy plants, whereas severe winds did not always. They also noted the immense value of using remote sensors to map damage to crops and property, rather than relying upon somewhat sparse spotter and insurance reports.

\section{The 4 July and 20 July 2003 Dakota hailswaths}

\section{a. Identifying devegetated hailswaths}

To identify potential hailswaths, we used Moderate Resolution Imaging Spectroradiometer (MODIS) data from the United States Geological Survey's (USGS) Earth Resources Observation Systems (EROS) Data Center (EDC). Because of the very large size of complete MODIS files, we acquired only the red image (band 1), resampled to $1000 \mathrm{~m}$, to search for vegetation anomalies. This spectral band $(620-670 \mathrm{~nm})$ highlights the contrast between low reflectance of a surface with dense green vegetation and the much higher reflectance of a surface with bare soil or dried vegetation. Thus, areas exhibiting higher red reflectance in characteristic long, narrow shapes were candidate devegetated hailswaths. The 4 and 20 July hailswaths are evident in such images, as shown in Figs. 2a and 2d.

Devegetated areas were also identified by an abrupt decrease in the NDVI between sequential measurements during the growing season (Bentley et al. 2002; Henebry and Ratcliffe 2003). We acquired the MODIS NDVI 7-day maximum value composites generated by EDC. These data were compiled sequentially, and we produced temporal difference images by subtracting each composite from the following one. Areas that exhibited decreased NDVI values between successive images (in a characteristic shape) were candidate devegetated hailswaths. The 4 and 20 July hailswaths are also evident in these images, as shown in Figs. $2 b$ and 2e.

Preliminary SPC reports of severe hail and wind for the storm dates (4 and 20 July) were then geographically superposed on the MODIS imagery. Because reports of large hail (at least $3 / 4$ in. or $1.91 \mathrm{~cm}$ ) occurred within or near the candidate July devegetated hailswaths in the Dakotas, they were considered "confirmed." The boundaries of each devegetated hailswath were then manually digitized onto the NDVI temporal difference composites within a GIS. 
a) 8-14 July NDVI image and 4 July hailswath

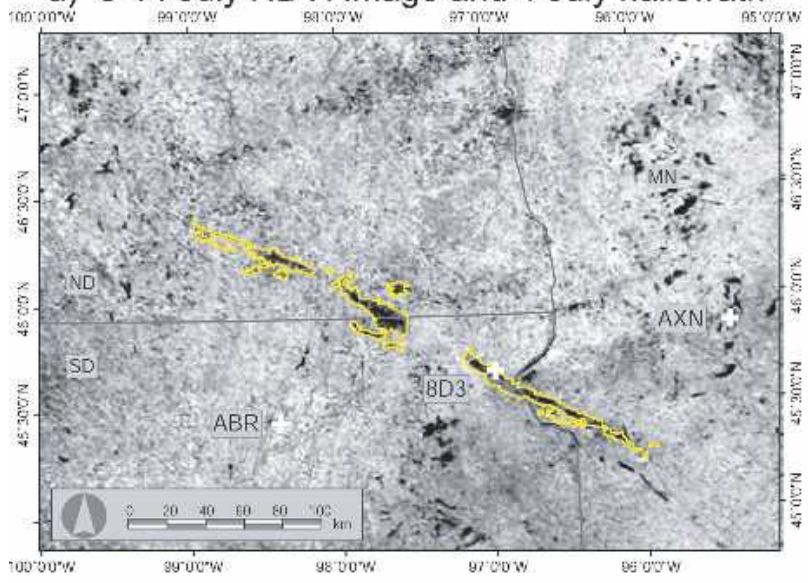

b) NDVI difference image and 4 July hailswath

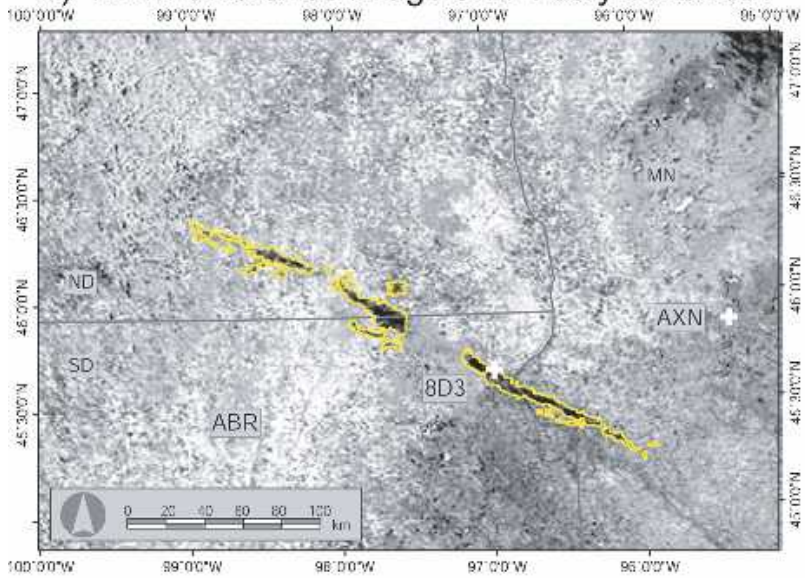

c) 4 July hailswath persistence

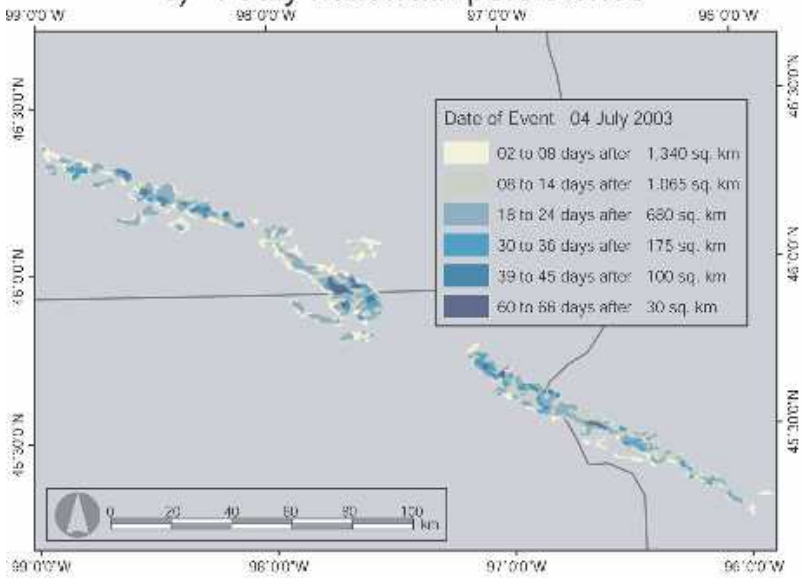

d) 22-28 July NDVI image and 20 July hailswath

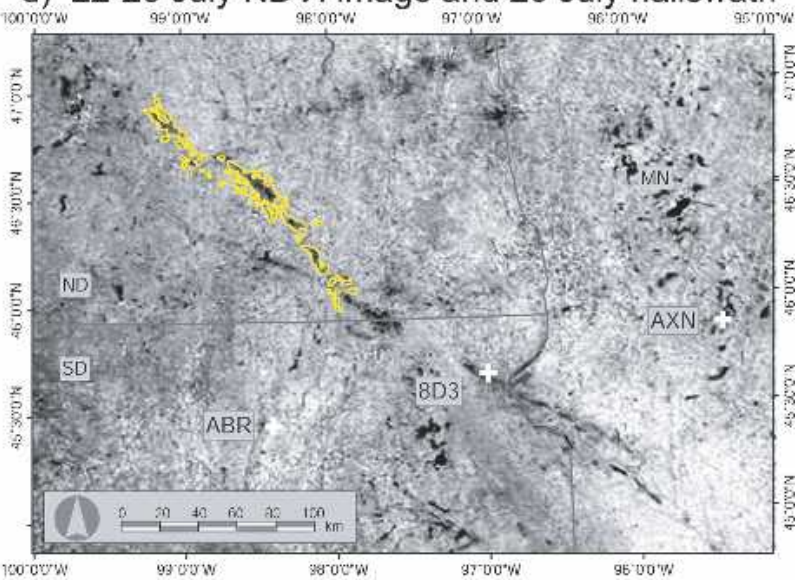

e) NDVI difference image and 20 July hailswath

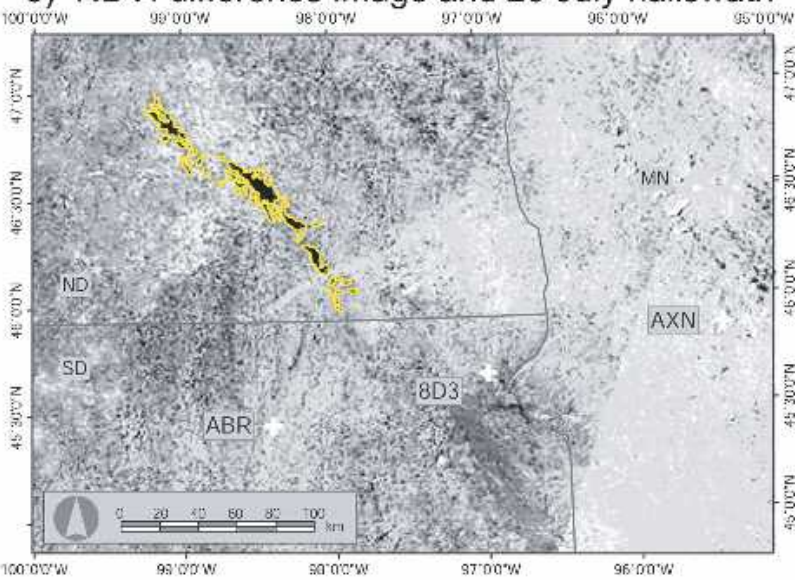

f) 20 July hailswath persistence

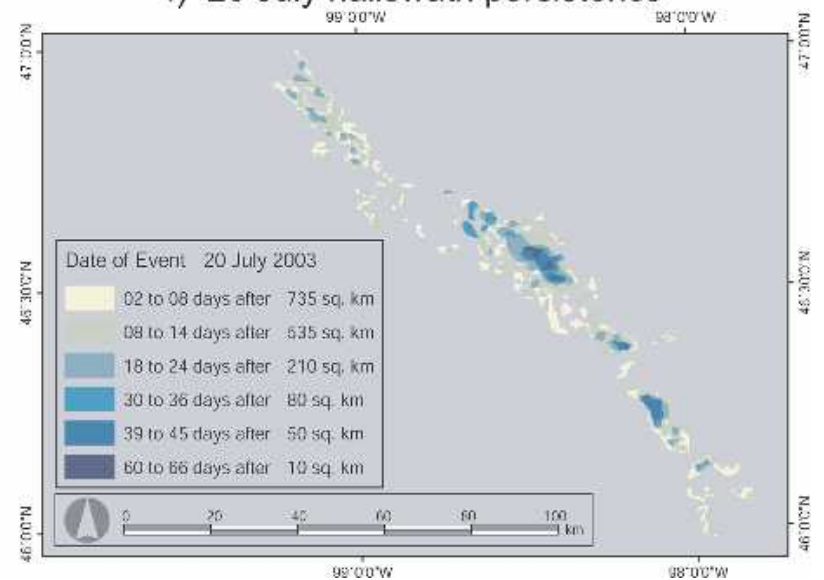

FIG. 2. MODIS NDVI 500-m images depicting the 4 and 20 Jul 2003 devegetated hailswaths. (a) Composite for 8-14 Jul, with the 4 Jul hailswath highlighted in yellow. (b) Temporal difference image, generated by subtracting the 8-14 Jul composite [(a)] from the 2-8 Jul composite, with the 4 Jul hailswath highlighted in yellow. (c) Spatial map of persistence of the 4 Jul 2003 devegetated hailswath. (d) Composite for 22-28 Jul, with the $20 \mathrm{Jul}$ hailswath highlighted in yellow. (e) Temporal difference image, generated by subtracting the 22-28 Jul composite [(d)] from the 18-22 Jul composite, with the 20 Jul hailswath highlighted in yellow. (f) Spatial map of persistence of the $20 \mathrm{Jul} 2003$ devegetated hailswath. Locations for observing stations ABR, 8D3, and AXN (referred to in the text) are denoted by crosses in (a) and (b). Notably, the devegetated hailswath from 4 Jul is still visible in the 20 Jul imagery [(d)]. The linear feature southeast of the 4 Jul hailswath [in (a), (b), and (d)] is the Red River of the North. 
We calculated the hailswath characteristics from this time series of digitized polygons, which served as the surrogate for the devegetated zone. To find the length of the devegetated zone, we calculated the length of the major axis of an ellipse that minimally circumscribed the streak. We then reduced this measurement to include only the devegetated areas within the ellipse, because the patterns of vegetation damage were spatially discontinuous. The width was taken as the widest portion of the devegetated hailswath. After delineating the devegetated hailswaths, we could then evaluate their persistence. We took the NDVI composite image just prior to the hail event as a baseline and then computed differences from each subsequent composite until the devegetated hailswath was either no longer distinguishable or had ceased changing in size. By assessing persistence on a pixel-by-pixel basis, the spatial structure of a hailswath's persistence can be usefully mapped, as in Figs. 2c and 2f.

\section{b. The 4 July hailswath}

A strong mesoscale convective system (MCS) crossed the Dakotas early on 4 July 2003 and produced numerous reports of severe winds and hail, along with significant crop and property damage. Hundreds of thousands of acres of crops were damaged in North Dakota alone, including some farms that suffered $100 \%$ losses and some counties that lost roughly one-third of their crops (DEM 2003). A devegetated hailswath was confirmed in the days following the storm (Figs. 2a,b), using the method outlined in section 3a. The hailswath that appeared following the 4 July event measured approximately $1340 \mathrm{~km}^{2}$ in area, $230 \mathrm{~km}$ in length, and $12.5 \mathrm{~km}$ in width, making it a relatively large example with respect to the hailswath population studied by Henebry and Ratcliffe (2003). The area of devegetation was persistent, decreasing monotonically in time with roughly $10 \%$ of the original devegetated zone still evident 6 weeks after the event (Figs. 2c and 3).

The initial thunderstorms that led to the hailswathproducing convective system of early 4 July were initiated around 2000 UTC on 3 July in the vicinity of a dryline over eastern Montana (Fig. 4a) and became linearly organized into a strong MCS (see Fig. 5). As the convective system moved east-southeastward, roughly parallel to a stationary front (Fig. 4a) and somewhat right of the westerlies aloft (Fig. 4b), it began to encounter moister lower-tropospheric air with significant potential buoyancy: at 0000 UTC the mixed-layer CAPE at Aberdeen, South Dakota (ABR), was $1742 \mathrm{~J}$ $\mathrm{kg}^{-1}$ compared to $598 \mathrm{~J} \mathrm{~kg}^{-1}$ at Bismarck, North Dakota (BIS; locations shown in Fig. 4). The ABR and BIS soundings further revealed significant deep-layer wind shear $(0-6-\mathrm{km}$ vector wind difference of $25-30$ $\mathrm{m} \mathrm{s}^{-1}$ ) and storm-relative helicity (SRH; 0-3 km value exceeding $250 \mathrm{~J} \mathrm{~kg}^{-1}$ ), suggesting an environment supportive of supercells (e.g., Rasmussen and Blanchard 1998), which are well known to produce very large hail (e.g., Johns and Doswell 1992). Indeed, for much of the system's lifetime, the strongest cell within the quasilinear convective region exhibited a prolific mesocyclone (weakly evident in Fig. 5b) and large echo overhang with bounded weak echo region (BWER) aloft (not shown).

From roughly 0300 UTC onward, the MCS produced significant hail and strong surface winds, as revealed by

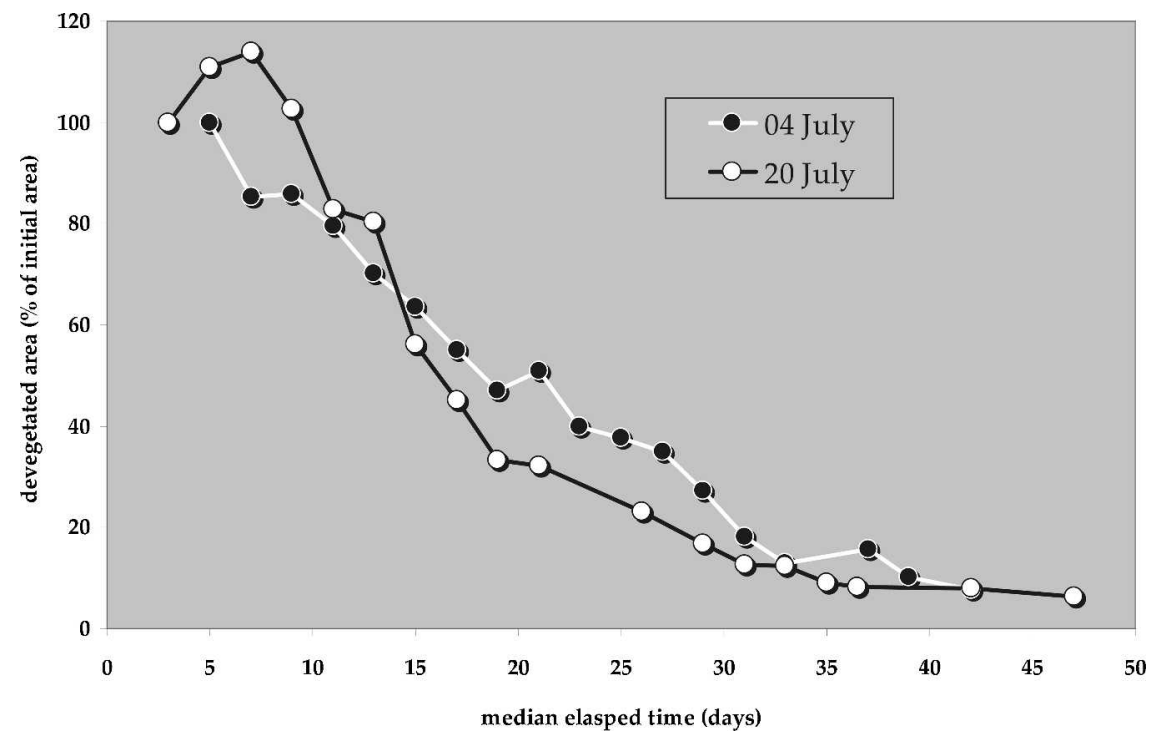

FIG. 3. Persistence of the 4 and 20 Jul devegetated hailswaths expressed as a fraction of their initial areas vs elapsed time. The initial swath areas were $1340 \mathrm{~km}^{2}$ for $4 \mathrm{Jul}$ and $644 \mathrm{~km}^{2}$ for $20 \mathrm{Jul}$. 
a)

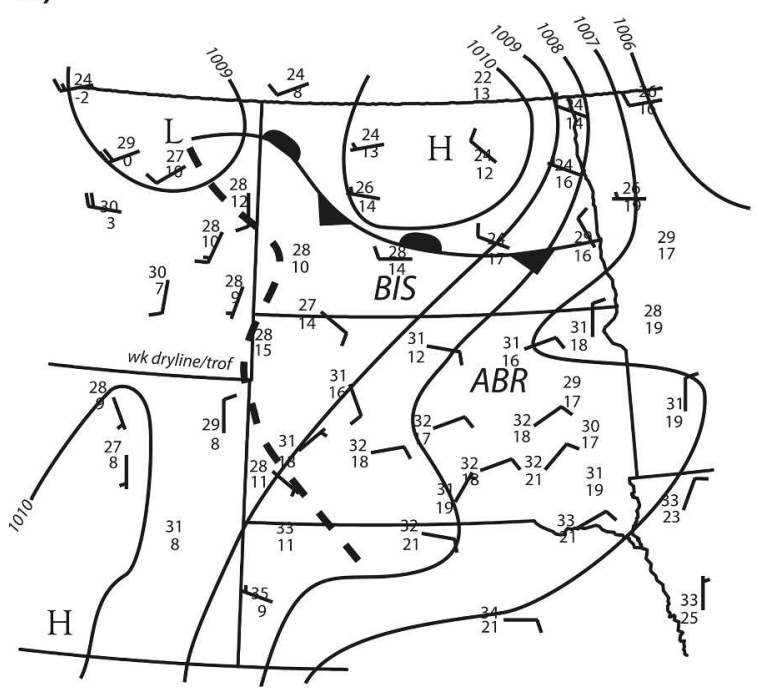

b) 0000 UTC 4 July 2003 ETA analyzed $500 \mathrm{hPa}$ heights and winds

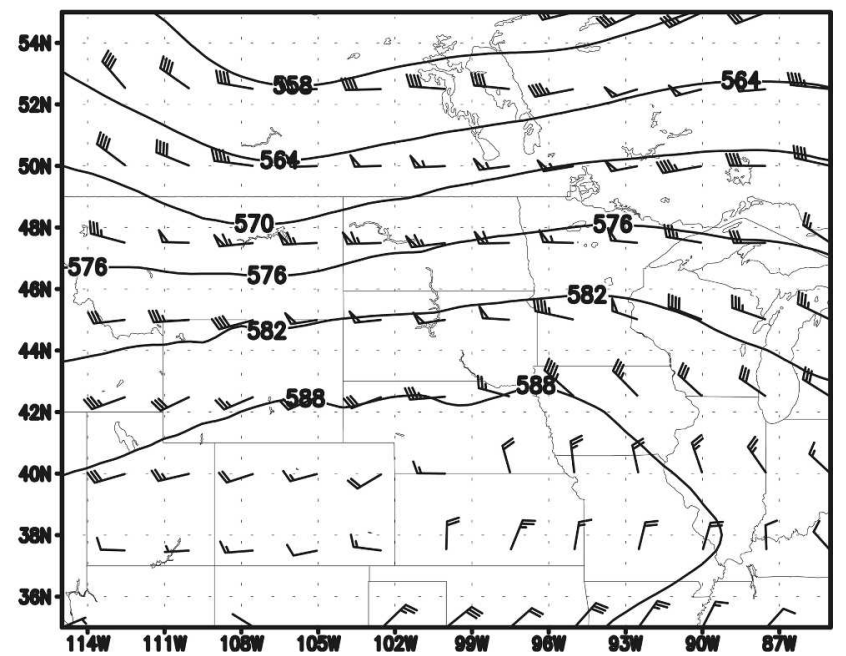

FIG. 4. Overview of the synoptic environment for the 4 Jul 2003 hailstorm: (a) 1900 UTC 3 Jul surface temperature $\left({ }^{\circ} \mathrm{C}\right)$, dewpoint temperature $\left({ }^{\circ} \mathrm{C}\right)$, and winds $\left(\mathrm{m} \mathrm{s}^{-1}\right)$ plotted in standard station model format, with manual analyses of surface pressure reduced to mean sea level (contours, $\mathrm{hPa}$ ) and boundary positions; (b) Eta Model analysis of 0000 UTC 4 Jul 500-hPa heights (dam) and winds $\left(\mathrm{m} \mathrm{s}^{-1}\right)$. Flags are $25 \mathrm{~m} \mathrm{~s}^{-1}$, barbs are $5 \mathrm{~m} \mathrm{~s}^{-1}$, and half barbs are $2.5 \mathrm{~m} \mathrm{~s}^{-1}$. The locations of BIS and ABR are shown in (a).

severe weather reports (golf ball-sized hail and winds up to $40 \mathrm{~m} \mathrm{~s}^{-1}$ ), large inbound velocities measured by Doppler radar (exceeding $30 \mathrm{~m} \mathrm{~s}^{-1}$ in Fig. 5b), and high values for radar hail-detection parameters. ${ }^{1}$ Around this time, the devegetated hailswath began to be produced beneath the predominant supercell within the convective line (Fig. 5). The terminus of the devegetated hailswath appears to have occurred soon after 0530 UTC, during which time the storm became notably less organized and began to weaken. The time period from roughly 0410 to 0430 UTC appears to correspond with a break in the devegetated hailswath (roughly centered within the hailswath depicted in Figs. 2a,b). Radar-derived hail parameters did not change much during this time period, but the 2000 National Land Cover Dataset (Homer et al. 2002) shows a distinct change in land cover from croplands to grasslands and wetlands in the $\operatorname{area}^{2}$ (the Prairie Couteau), highlighting the importance of land-cover type in the visibility of devegetated hailswaths. The observed swath of devegetation can therefore be understood as repre-

\footnotetext{
${ }^{1}$ We investigated reflectivities at $8 \mathrm{~km} \mathrm{AGL}$, following Lemon (1980) and Witt et al. (1998), as well as vertically integrated liquid (VIL), following Burgess and Lemon (1990), Amburn and Wolf (1997), and Billet et al. (1997).

${ }^{2}$ The land cover in Marshall County, South Dakota, is roughly $50 \%$ grasslands, $20 \%$ corn, $20 \%$ soybeans, and $10 \%$ small grains. However, areas in which the hailswath was visible comprise roughly $80 \%-90 \%$ cropland, whereas in the swath gap, they comprise roughly $70 \%$ mixed grassland/cropland and only $30 \%$ dedicated cropland (S. Thompson 2004, Marshall County Farm Service Agency, personal communication).
}

senting a positive juxtaposition of the system's production of significant hail, strong winds, and land cover that was particularly susceptible to damage from windblown hail.

\section{c. The 20 July hailswath}

A series of intense, isolated thunderstorms moved southeastward from central North Dakota into northeastern South Dakota during the early hours of 20 July 2003. At least 130000 acres of cropland were damaged, including some farms which suffered $100 \%$ losses (DEM 2003). In the days following the storms, a second devegetated hailswath was confirmed, partly overlapping the first hailswath and measuring $127.6 \mathrm{~km}$ in length and $10.3 \mathrm{~km}$ in width (Figs. 2d,e). Unlike the 4 July hailswath, the devegetation from the 20 July event did not exhibit a monotonic decay in area with time (Fig. 3). The initial devegetated area was measured as $644 \mathrm{~km}^{2}$ in the 20-26 July NDVI composite, but attained a maximum of $733 \mathrm{~km}^{2}$ in the 24-30 July composite (Figs. 2f and 3). This increase is likely attributable to the fact that some hail-damaged vegetation (especially when plants are more mature) takes time to die. ${ }^{3}$ As with the 4 July case the swath was persistent, with roughly $10 \%$ of the original devegetated area still evident 5-6 weeks after the 20 July event (Figs. 2f and 3 ).

\footnotetext{
${ }^{3}$ For this reason, it is common practice for crop-hail insurance adjusters to visit hail-damaged fields 7-10 days following a hailstorm (Peters et al. 2000).
} 

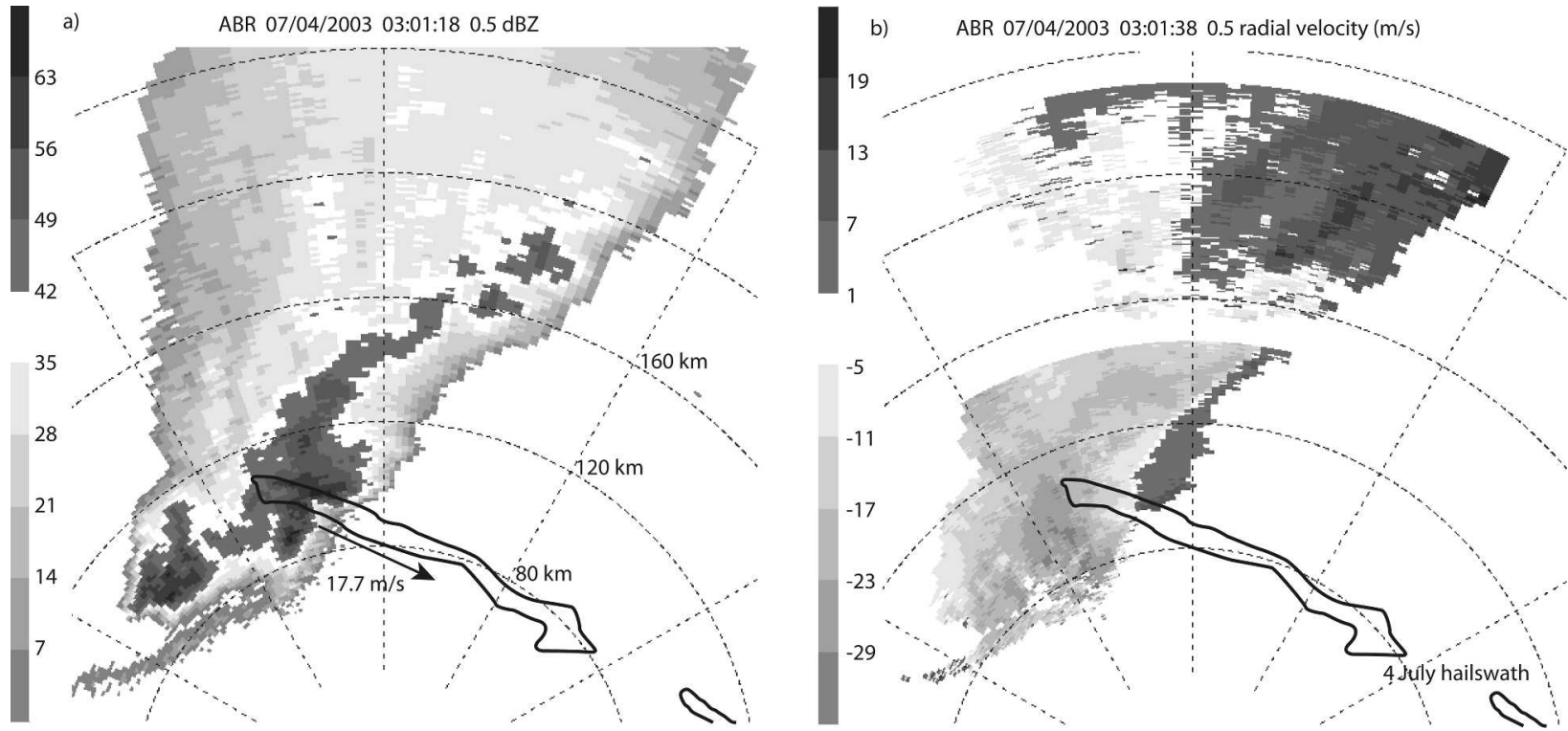

FIG. 5. Radar base scan images for 0301 UTC 4 Jul 2003 from ABR: (a) reflectivity (dBZ) and (b) radial velocity (m s${ }^{-1}$ ). The principal storm's motion is indicated by the vector in (a). The 4 Jul hailswath's observed position is outlined, as identified in (b). Range rings are plotted every $40 \mathrm{~km}$, as identified in (a). Values for each panel are shaded as shown.

The 20 July storms were initiated near BIS, north of a weak stationary front (Fig. 6a) between 0400 and 0500 UTC. Regional soundings again revealed that, under northwesterly upper-tropospheric flow (Fig. 6b), the storms were moving southeastward into moister lowertropospheric air with enhanced potential buoyancy (0000 UTC mixed-layer CAPE of $1897 \mathrm{~J} \mathrm{~kg}^{-1}$ at 0000 UTC at ABR, as compared to $252 \mathrm{~J} \mathrm{~kg}^{-1}$ at BIS). As on 4 July, the environment appeared to be favorable for supercellular thunderstorms, with $0-6-\mathrm{km}$ vector wind differences exceeding $20 \mathrm{~m} \mathrm{~s}^{-1}$ and $0-3 \mathrm{~km} \mathrm{SRH} \mathrm{ex-}$ ceeding $150 \mathrm{~J} \mathrm{~kg}^{-1}$.

By approximately 0630 UTC, the first of three successive cells began to exhibit increased hail-detection parameters and to generate severe hail reports. This first storm exhibited supercellular characteristics from roughly 0700 to 0930 UTC (Fig. 7). Two additional cells followed in kind through 1000 UTC, both of which were somewhat weaker than the first storm, but which also exhibited supercellular characteristics. The behav- a)

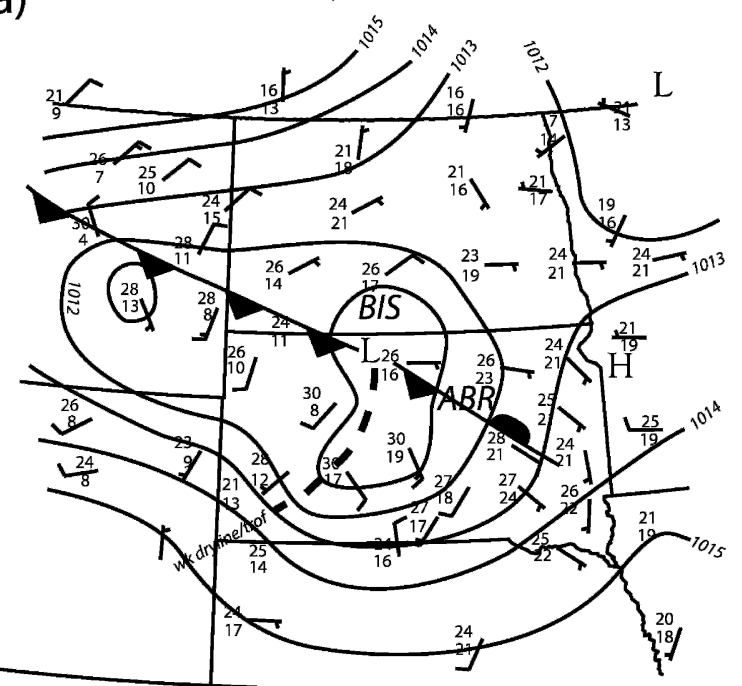

b)

0000 UTC 20 July 2003

ETA analyzed $500 \mathrm{hPa}$ heights and winds

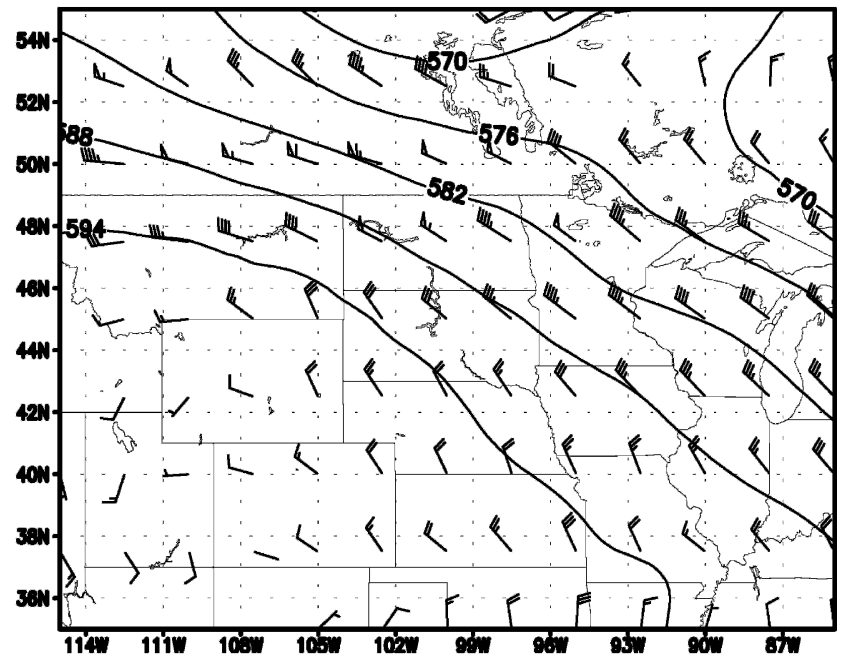

FIG. 6. Same as Fig. 4 except for (a) 0400 and (b) 0000 UTC 20 Jul. 


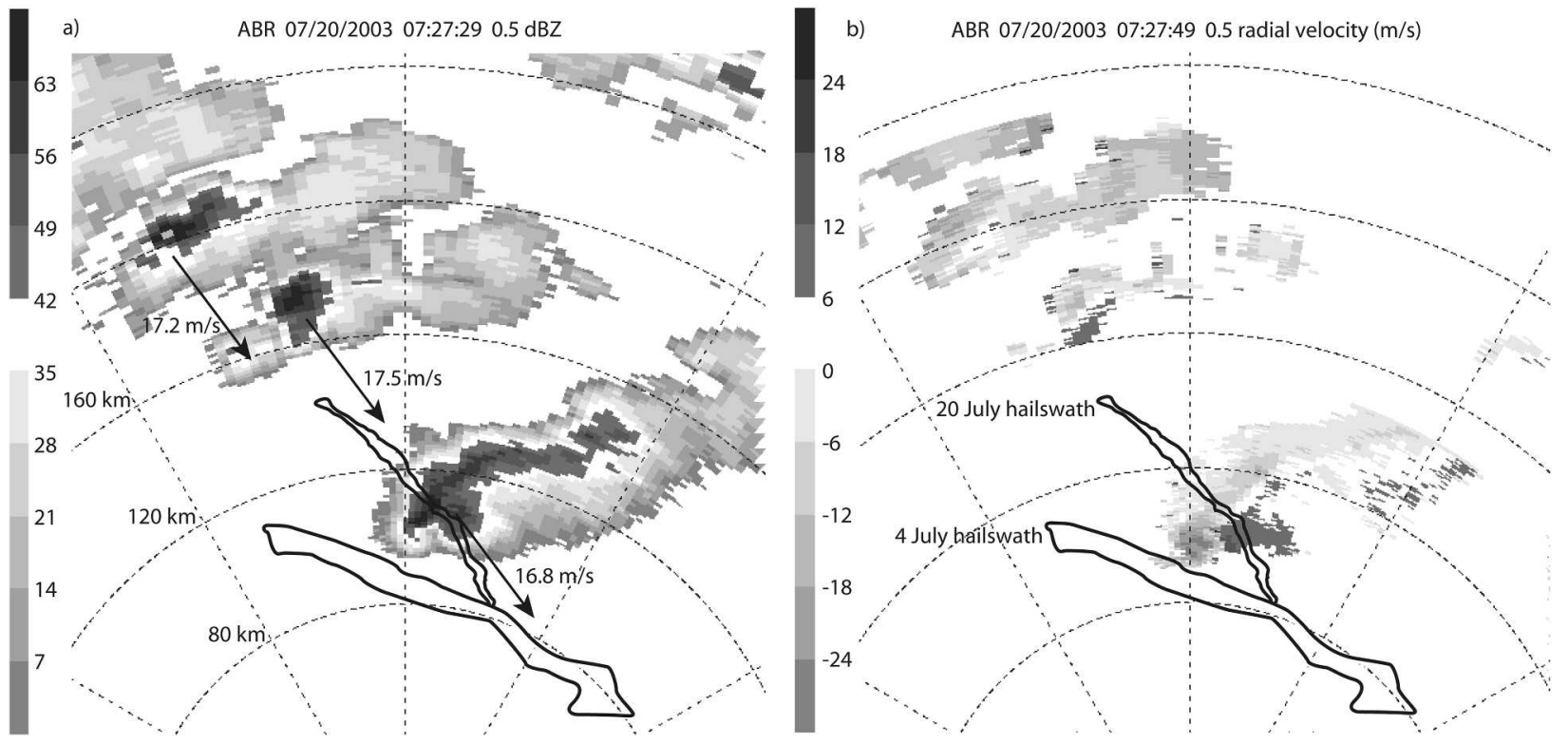

FIG. 7. Radar base scan images for 0727 UTC 20 Jul 2003 from ABR: (a) reflectivity (dBZ) and (b) radial velocity ( $\mathrm{m} \mathrm{s}^{-1}$ ). The principal storms' motions are indicated by the vectors in (a). The 4 and 20 Jul hailswaths' observed positions are outlined, as identified in (b). Range rings are plotted every $40 \mathrm{~km}$, as identified in (a). Values for each panel are shaded as shown.

ior of the 20 July 2003 storms is discussed further in section 5c. Because the area is sparsely populated, and because the devegetated hailswath was only observed after the episode, it is impossible to determine which among the storms actually produced the hailswath. Although the first among the three storms had the most pronounced mesocyclone, and was the only one to produce any severe wind reports, each of the three storms evinced very high hail-detection parameters, so it is quite possible that each contributed, much as originally envisioned by Changnon (1970). The storms traversed similar discontinuities in land cover to those experienced by the 4 July MCS. Severe winds were apparently not widespread, although along the swath gusts up to 50 $\mathrm{m} \mathrm{s}^{-1}$ were reported and, in Dickey, North Dakota (nearly centered within the hailswath), nearly every north-facing window was damaged by wind-blown hail (DEM 2003). Analysis again reveals that the observed hailswath represented the juxtaposition of significant severe hail and wind production with the existence of a land cover that was susceptible to damage.

\section{Observed temperature perturbations associated with the hailswaths}

Anthes (1984) noted that decreased vegetative cover might increase the albedo of the surface but, more significantly, should increase the Bowen ratio. Indeed, Mahfouf et al. (1987) found in comparing simulated surface fluxes over grass-covered and bare ground that the total surface fluxes remained roughly the same, whereas the Bowen ratio increased from roughly 1:1 to roughly $4: 1$. The resulting comparative increase in the surface sensible heat flux would increase daytime temperatures in the devegetated area. Segal et al. (1988) reviewed several such examples of "noticeable temperature differences" $\left(1^{\circ}-2^{\circ} \mathrm{C}\right.$, and as large as $\left.4.5^{\circ} \mathrm{C}\right)$ between vegetated areas and bare soil, and pointed out that the basic effects of differences between vegetated and bare ground are further enhanced when the growing vegetation is irrigated. The data presented by Doran et al. (1998) revealed that these kinds of differences in land cover (e.g., growing versus harvested fields) can actually play a dominant role in observed gradients in surface fluxes. Given the extreme, persistent devegetation present in hailswaths, it is reasonable to hypothesize that there may be persistent local temperature anomalies owing to differences in the Bowen ratio between a dry devegetated strip of land and the surrounding irrigated, crop-covered ground. We assess this hypothesis by comparing observations prior to and following the creation of the 4 and 20 July hailswaths.

In particular, because of the 4 July devegetated hailswath's large size, its impacts upon the regional surface temperature were well observed by GOES infrared satellite imagery when skies were clear. During the month prior to the devegetated hailswath's formation, clearday infrared satellite measurements of the region revealed relatively small-scale, low-magnitude inhomogeneities in temperature (not shown). During the month following the devegetated hailswath's formation, however, the swath was characterized by increased temperatures in comparison to its surroundings. For example, on clear days such as 15 July, the swath's signature was quite pronounced (Fig. 8a). Although it is not possible here to show every example of the swath's 

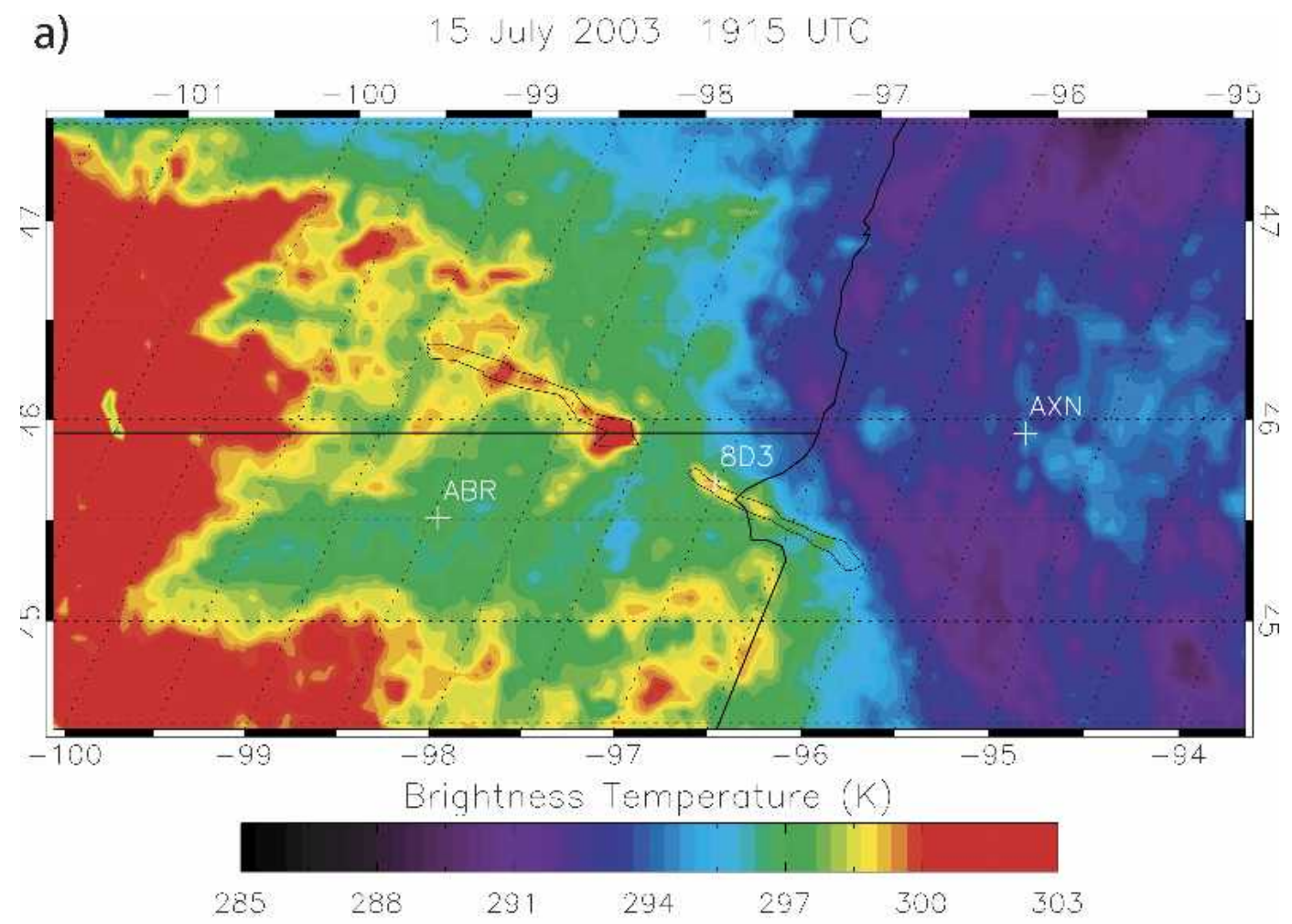

b) $\quad 9 \cdot 5$ UTC overace for 7 clear dcys

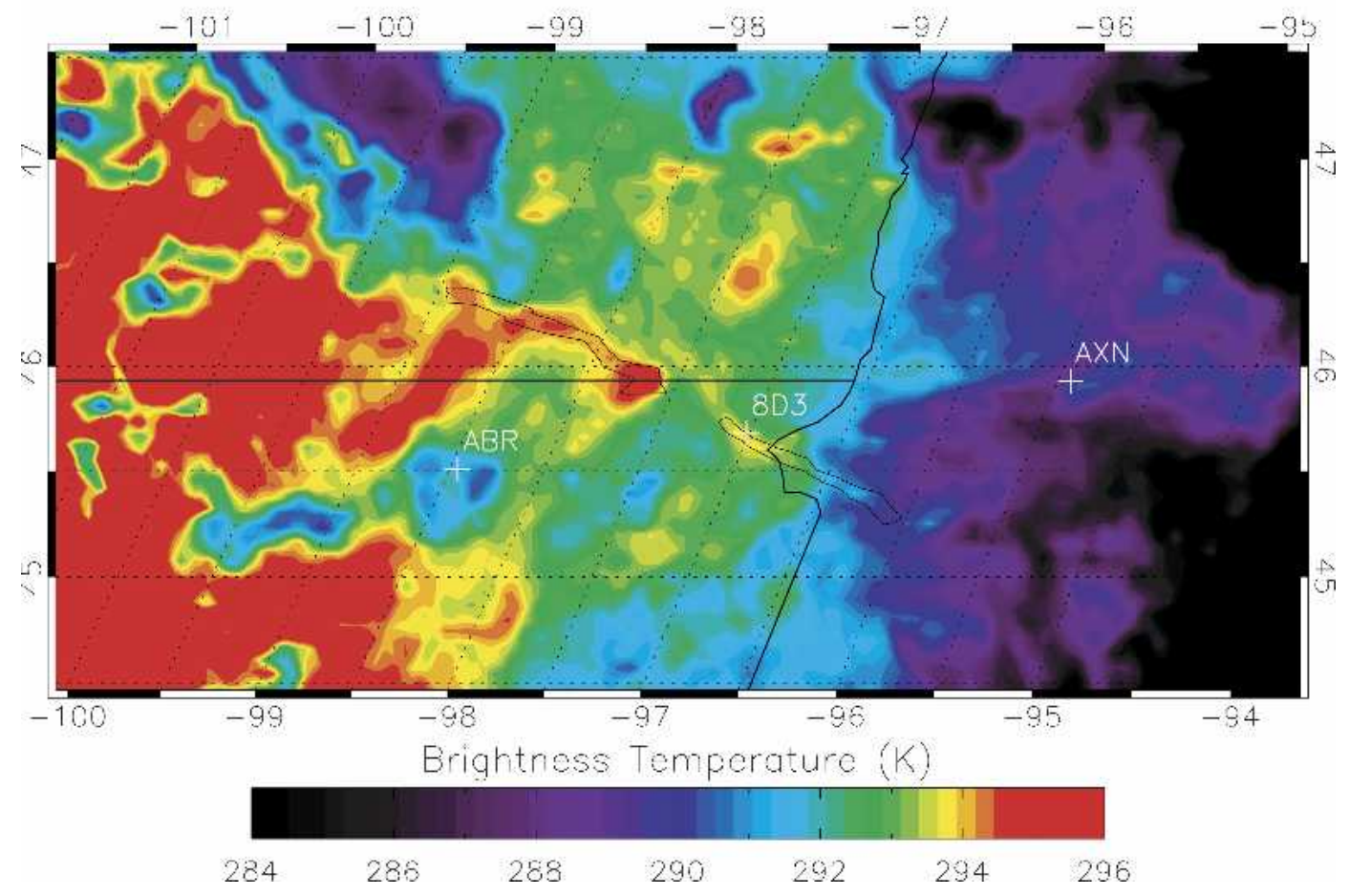

FIG. 8. GOES infrared brightness temperatures (K) for (a) 1915 UTC 15 Jul 2003 and (b) 1915 UTC averaged among 7 clear days $(4,13,14,15,19,24$, and 28 Jul 2003). Brightness temperatures are shaded as shown for each panel. 
local temperature perturbation, we observed it in the GOES infrared data during 12 different days from 4 to 28 July, often with magnitudes exceeding $4 \mathrm{~K}$. On these days, the temperature maximum was most obvious between 1600 and 2300 UTC (1000 and 1700 LST), although on several days we were only able to observe the temperature maximum for part of the time, owing to intervening cloud cover. The persistent nature of the temperature anomaly is well illustrated by compositing the data from the 7 days on which it was clear over the swath at 1915 UTC (Fig. 8b). Although they appeared on several days, such GOES-observed temperature anomalies were less obvious for the 20 July swath, likely because it was smaller, and because it reached its maximal extent during a series of primarily overcast days.

Serendipitously, the surface-observing station in Sisseton, South Dakota, was located on the periphery of the 4 July devegetated hailswath (shown by identifier 8D3 in Figs. 2 and 8), enabling additional quantitative comparisons between the swath and its surroundings. ${ }^{4}$ We compared the temperature and dewpoint at $8 \mathrm{D} 3$ to two other nearby surface-observing stations, ABR and Alexandria, Minnesota (AXN) ${ }^{5}$ which were located on opposite sides, and beyond the edge of, the devegetated hailswath (also shown in Figs. 2 and 8).

On average, during the 30 days prior to the formation of the swath (4 June-3 July), 8D3 was $0.24^{\circ} \mathrm{C}$ warmer than the average between ABR and AXN and had a dewpoint that was $0.59^{\circ} \mathrm{C}$ higher than the average between ABR and AXN. During the 30 days following the formation of the swath (4 July-2 August), 8D3 was $1.11^{\circ} \mathrm{C}$ warmer than $\mathrm{ABR}$ and $\mathrm{AXN}$ and had a dewpoint that was $0.25^{\circ} \mathrm{C}$ higher than $\mathrm{ABR}$ and $\mathrm{AXN}$. In other words, following the formation of the devegetated hailswath, $8 \mathrm{D} 3$, which was within the swath near the edge, increased in temperature by roughly $0.9^{\circ} \mathrm{C}$ in comparison to its surroundings, and decreased in dewpoint by roughly $0.3^{\circ} \mathrm{C}$ in comparison to its surroundings (Fig. 9). Corrected for serial autocorrelation, both of these differences are statistically significant at the 0.95 level ( $p=0.00004$ for temperature; $p=0.02$ for dewpoint temperature). The observed warming and drying are consistent with a local increase in the Bowen ratio owing to the removal of vegetation. It is also likely that farmers stop irrigating destroyed crops, and this lack of irrigation would further impact the Bowen ratio by ensuring that the soil was comparatively very dry.

During the 31st-60th days after creation of the swath (3 August-1 September), as native vegetation progres-

\footnotetext{
${ }^{4}$ Unfortunately, there was no observing station within $20 \mathrm{~km}$ of the $20 \mathrm{Jul}$ hailswath, so no such comparison was possible for it.

${ }^{5}$ We used AXN because, although there were other observing stations in Minnesota that were on the proper side of, and in closer proximity to, the hailstreak, these other stations did not report temperatures in tenths of degrees Celsius.
}

sively overgrew it, temperatures within the swath at 8D3 fell back toward those of the surrounding region $\left(0.42^{\circ} \mathrm{C}\right.$ higher than ABR and AXN; Fig. 9a). However, there was not a corresponding increase in the dewpoint temperature (it was only $0.14^{\circ} \mathrm{C}$ higher than $\mathrm{ABR}$ and AXN; Fig. 9b), which might have been expected from a simple decrease in the Bowen ratio owing to new vegetation. Unfortunately, inferring the Bowen ratio from the observed temperature and humidity at instrument height (typically, $2 \mathrm{~m}$ ) is inexact because these measurements are also influenced by horizontal advection. As shown by Segal et al. (1988), solenoidal circulations generated by patches of warm, dry ground will entail the inflow of moister low-level air from the surrounding environment. Therefore, the dewpoint temperature at 8D3 during the 4 July-2 August period is probably higher than what would be expected solely owing to latent heat fluxes from the bare soil (indeed, 8D3's dewpoint temperature is not even lower than that of its surroundings; Fig. 9b). This effect could then mask any increase in latent heat fluxes (decrease in Bowen ratio) during the 3 August-1 September period. Even so, the changes in temperature and humidity over the 4 June-1 September period are broadly consistent with the changes in Bowen ratio that would be expected when transforming the land surface from irrigated cropland, to dry soil, to non-irrigated native vegetation.

During 4 July-2 August, the increase in 8D3's temperature was largest between 1600 and 2000 LST (Fig. 9), lagging the GOES infrared data by roughly 3-4 h. This may be partly attributable to the fact that GOES measures the ground temperature (on clear days), whereas meteorological stations measure the air temperature, which trails behind owing to the time required for the surface fluxes to act; indeed, by mid-late afternoon on most days, the infrared signal had largely disappeared. In addition, because the GOES infrared data were only useful during clear periods, it was a much smaller dataset. Interestingly, the data also reveal a comparative temperature increase approaching $1^{\circ} \mathrm{C}$ for much of the period from 0300 to 0700 LST. The nocturnal increase in temperature over the devegetated hailswath was not obvious in the GOES data on clear nights, and hence we attribute it to increases in temperature on cloudy evenings, during which the surface radiation deficit is smaller and the corresponding downward buoyancy flux is minimized. On such nights the swath would remain warmer than its surroundings into the nighttime hours. We discuss one possible impact of this nocturnal maximum in section $5 \mathrm{c}$.

In short, there is evidence from both GOES infrared and surface observations that local warming and drying occurred following the creation of the 4 July devegetated hailswath, and to a lesser degree the 20 July swath. Notably, the differences in temperature and humidity might be even larger in the middle of swaths; they were quite evident at $8 \mathrm{D} 3$, which is located near 
a)

Temperature: $8 \mathrm{D} 3-(\mathrm{ABR}+\mathrm{AXN}) / 2$

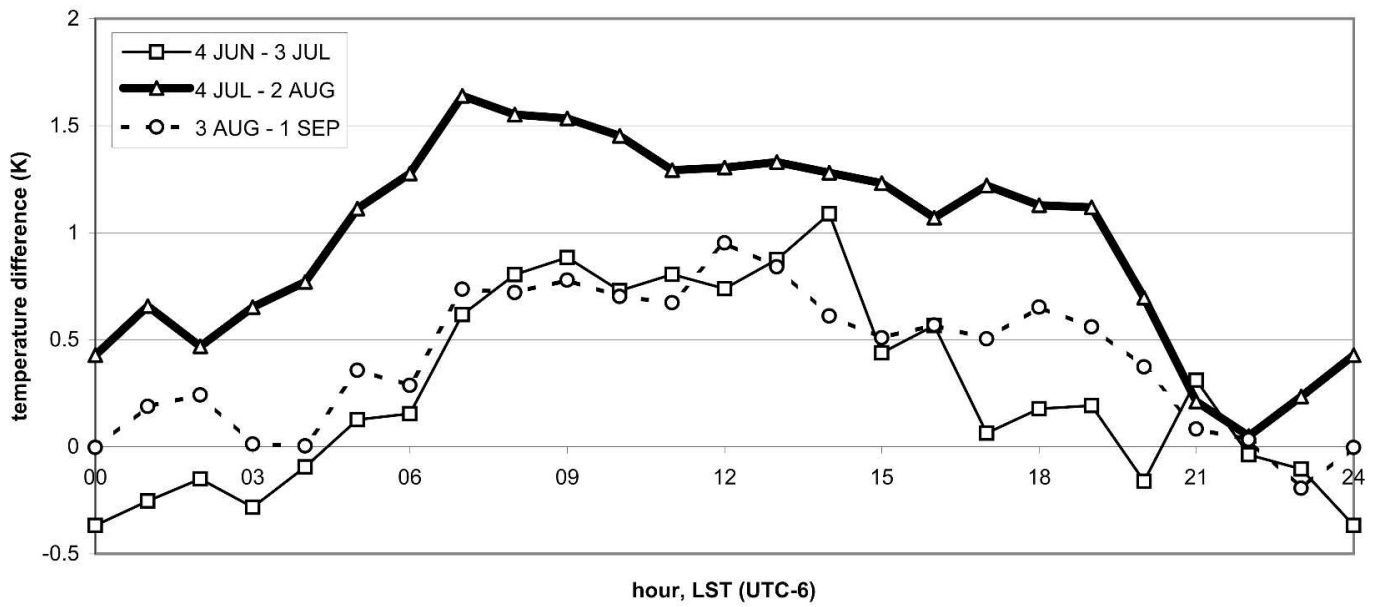

b)

Dewpoint temperature: 8D3 - (ABR+AXN)/2

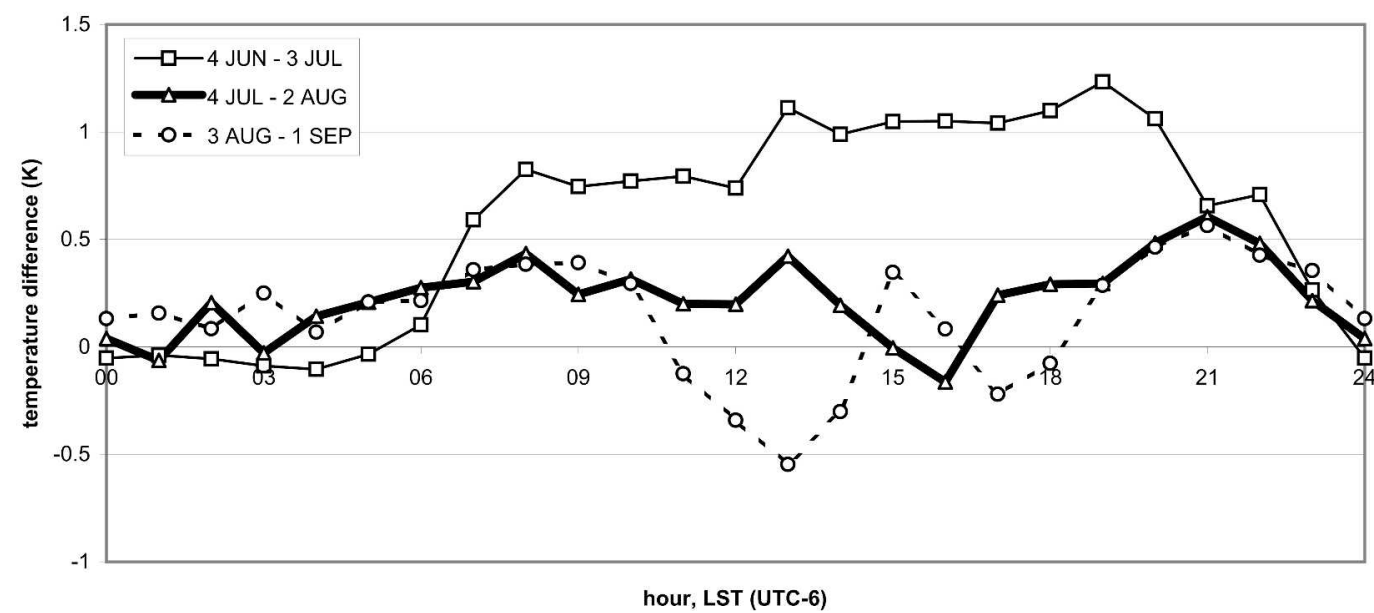

FIG. 9. Diurnal plot of the post-4 Jul change in the (a) temperature (K) and (b) dewpoint temperature (K) differences between $8 \mathrm{D} 3$ and the average of ABR and AXN. Data are plotted for 30 days prior to the 4 Jul hailswath's creation (4 Jun-3 Jul), 30 days following 4 Jul (4 Jul-2 Aug), and 31-60 days following 4 Jul (3 Aug-1 Sep), keyed as shown.

the edge of the 4 July devegetation and was not in the vicinity of the greatest GOES-indicated temperature perturbations (Fig. 8).

Recent observations suggest that the temperature excess beneath active boundary layer thermals may be as small as $1 / 3^{\circ} \mathrm{C}(\mathrm{P}$. Markowski 2003, personal communication). This suggests that the observed perturbations at 8D3 (and unobserved elsewhere within the swath) are likely to be important. We hypothesize that devegetated hailswaths may indeed produce sufficient buoyancy anomalies to influence convective behavior and address this in the remainder of the paper.

\section{Possible impacts of the hailswaths upon subsequent convection}

The aforementioned gradients in the surface sensible heat flux should be expected to impact convective avail- able potential energy (CAPE) and convective inhibition (CIN), and to impact the turbulent vigor, transports, and depth of the boundary layer (e.g., Pielke 2001, and the numerous works reviewed therein). These, in turn, may impact the development of moist convection. Yan and Anthes (1988) found that a single strip of dry land surrounded by moist ground could indeed enhance local convective development through an inland sea-breeze mechanism, and Avissar and Liu (1996) showed that, in simulations with strips of wet and dry land, the upward motions associated with landscape discontinuities could in some cases exceed the vertical velocities induced by turbulence, with the ascent focused over the dry land. Avissar (1992) noted that the contrast between the presence or absence of plants as ground cover had a very similar effect to the contrast between wet and dry land surfaces. Weaver 


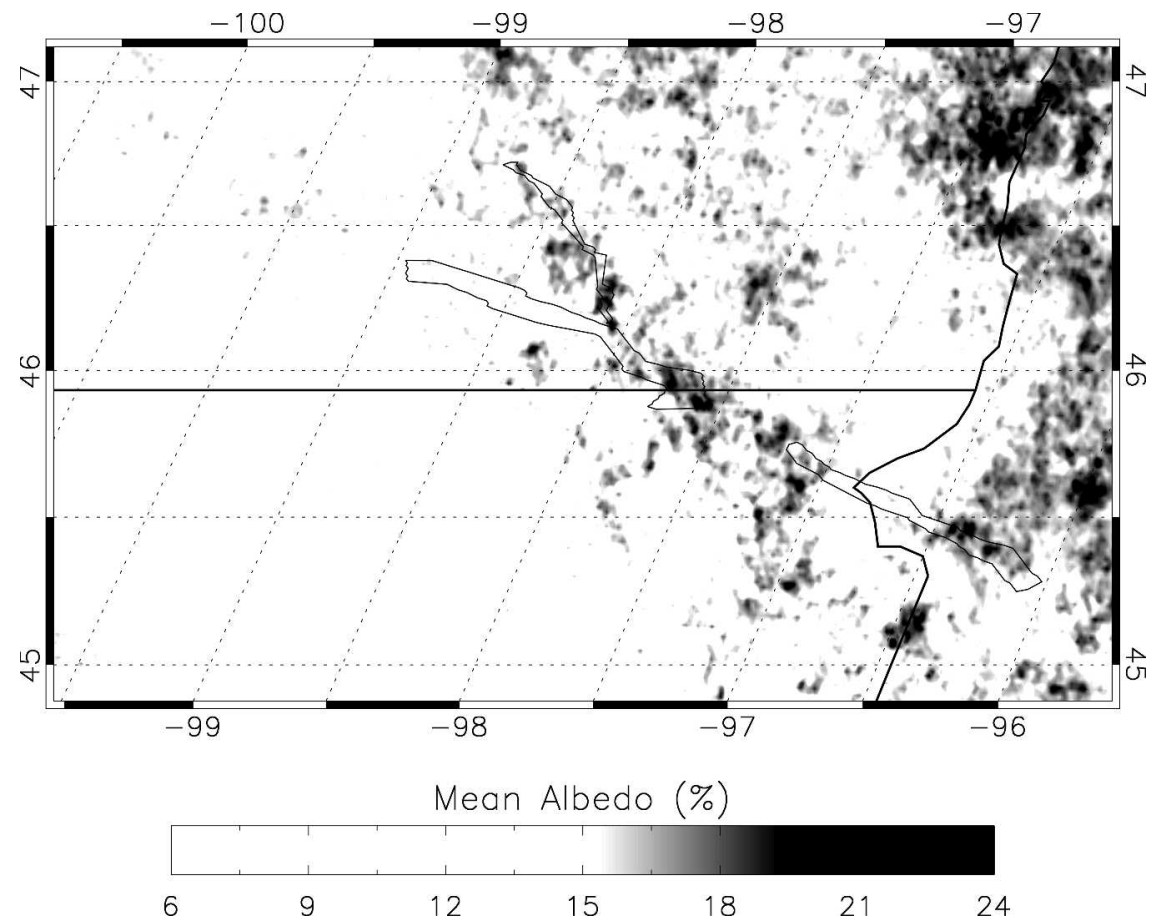

FIG. 10. Averaged 2115 UTC GOES channel-1 albedo from 13 days following creation of the Jul 2003 Dakota hailswaths. The data are from 9, 12, 15, 19, 21, 22, and 31 Jul and 2, 3, 6, 7, 11, and 12 Aug. Political boundaries and outlines of the 4 and 20 Jul hailswaths are drawn for reference. The grayscale spans 1 std dev above and below the population mean.

and Avissar (2001) reviewed numerous observational studies (e.g., Rabin et al. 1990; Cutrim et al. 1995) that were consistent with the preferred formation of cumuli in the late morning/early afternoon over devegetated areas, where the surface sensible heat flux was largest. Further, simulations by Chang and Wetzel (1991) showed that the observed development of tornadic storms in a weak synoptic regime might be related to spatial variations in soil moisture and vegetation.

The relevance of the above findings to devegetated hailswaths is not entirely clear, however. Yan and Anthes (1988) noted that, for a single strip of dry land to enhance convective development significantly, the strip of dry land needed to be fairly wide. Similarly, Rabin et al. (1990) found that on days with surface wind speeds exceeding $5 \mathrm{~m} \mathrm{~s}^{-1}$, wet or dry surface anomalies needed to be at least $20 \mathrm{~km}$ in diameter in order to induce differential cloud development. As reviewed by Weaver and Avissar (2001), the typical atmospheric response to surface heterogeneities with scales below 5 $\mathrm{km}$ is generally chaotic, whereas larger scales may yield organized mesoscale circulations. However, this result may in turn be sensitive to the atmospheric humidity and stability, as shown by Hong et al. (1995).

Might a devegetated hailswath organize cloudiness? In the weeks following the formation of the 4 and 20 July devegetated hailswaths, there were numerous days on which cloudiness appeared to be close to, and at least partly aligned with, the swaths' positions. Although it is not possible here to show each of these cases, the general behavior is partly evident in the afternoon (2115 UTC) average of albedo from 13 days

TABLE 1. Parameters describing configuration of the ARPS, version 5.1.0, for the idealized numerical simulations.

\begin{tabular}{|c|c|}
\hline Parameter & Setting \\
\hline Horizontal grid spacing & $1000 \mathrm{~m}$ \\
\hline Vertical grid spacing & $\begin{array}{l}400 \mathrm{~m} \text {, stretched from } 200 \\
\text { to } 625 \mathrm{~m}\end{array}$ \\
\hline Time step & $2.5 \mathrm{~s}$ \\
\hline Acoustic time step & $1.25 \mathrm{~s}$ \\
\hline Domain size & $380 \mathrm{~km} \times 380 \mathrm{~km} \times 19.8 \mathrm{~km}$ \\
\hline Lateral boundaries & Periodic \\
\hline Top and bottom boundaries & Free-slip plates \\
\hline Rayleigh damping layer & $\begin{array}{l}\text { Coefficient }=0.01667 \mathrm{~s}^{-1} \\
\quad \text { above } 15 \mathrm{~km}\end{array}$ \\
\hline Ice microphysics & $\begin{array}{l}\text { Lin et al. (1983); Tao and } \\
\text { Simpson (1993) }\end{array}$ \\
\hline Turbulent mixing & $\begin{array}{l}\text { 1.5-order prognostic TKE* } \\
\text { closure }\end{array}$ \\
\hline $\begin{array}{l}\text { Fourth-order computational } \\
\text { mixing coefficient }\end{array}$ & $\begin{array}{l}5.0 \times 10^{8} \mathrm{~m}^{4} \mathrm{~s}^{-4}, \text { horizontal } \\
\text { only }\end{array}$ \\
\hline Asselin filtering coefficient & 0.10 \\
\hline Divergence damping coefficient & 0.05 \\
\hline $\begin{array}{l}\text { Surface bulk transfer coefficient } \\
\text { for scalars }\end{array}$ & $3.0 \times 10^{-3}$ \\
\hline $\begin{array}{l}\text { Surface bulk transfer coefficient } \\
\text { for momentum }\end{array}$ & 0.0 \\
\hline Coriolis parameter & $0.0 \mathrm{~s}^{-1}$ \\
\hline
\end{tabular}

$*$ TKE $=$ turbulent kinetic energy. 


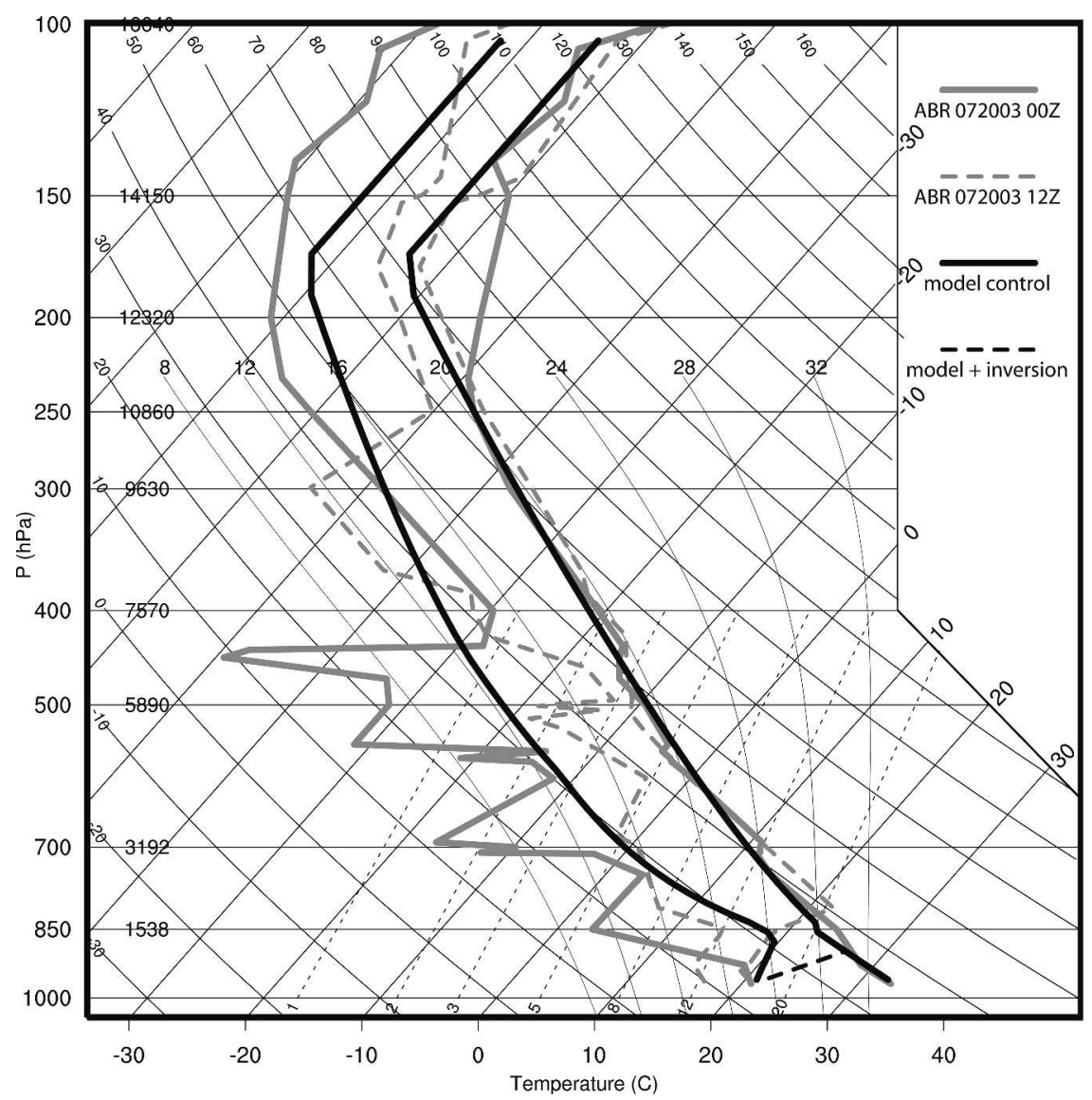

FIG. 11. Skew $T-\ln p$ diagram of the temperature and humidity soundings used in the idealized numerical experiments: most simulations used the control sounding (solid black); simulations with stabilized lower troposphere used the inversion sounding (dashed black). The model soundings are based on the analytic soundings of Weisman and Klemp (1982) and Parker and Johnson (2004), but have been tuned to reflect coarsely some of the features present near the swath on $20 \mathrm{Jul} 2003$ (the light gray profiles).

that were neither overcast nor completely clear (Fig. 10). Along many parts of the swaths, particularly those whose damage was most persistent (Figs. 2c,f), the mean albedo was somewhat higher than that in the swaths' immediate vicinity. Given the tantalizing possibility that awareness of hailswaths could improve convective forecasting, in this section we consider several potential impacts of the devegetation within the larger, 4 July 2003 Dakota hailswath, using idealized numerical simulations and two brief case studies.

\section{a. Idealized numerical simulations}

To determine whether it was physically reasonable for regional convective behavior to be influenced by the 4 July 2003 hailswath, we undertook a set of idealized numerical simulations using the Advanced Regional Prediction System (ARPS; Xue et al. 1995, 2000, 2001), version 5.1.0. The basic configuration of the model is summarized in Table 1.

The initial atmospheric condition was homogeneous and based upon the analytic convection soundings developed by Weisman and Klemp (1982) and Parker and Johnson (2004), but tuned to coarsely resemble observed soundings from ABR on 20 July 2003 (Fig. 11), a day on which convection was known to occur in the region. Surface fluxes were included, but in order to simplify interpretation, the soil temperatures were held constant throughout the simulations. Because the initial sounding already included a well-mixed afternoon boundary layer, our simulations were therefore simulating the differential effects of a hailswath upon the

TABLE 2. Maximum temperature perturbations (K) at lowest model grid level for various lower-tropospheric flow speeds and directions in the experiments without vertical wind shear. Daggers denote simulations in which deep convection occurred.

\begin{tabular}{lclc}
\hline \hline \multicolumn{1}{c}{ Surface winds } & $2.5 \mathrm{~m} \mathrm{~s}^{-1}$ & $5 \mathrm{~m} \mathrm{~s}^{-1}$ & $7.5 \mathrm{~m} \mathrm{~s}^{-1}$ \\
\hline Parallel to swath & $1.93 \mathrm{~K}^{\dagger}$ & $2.74 \mathrm{~K}^{\dagger}$ & $2.17 \mathrm{~K}^{\dagger}$ \\
$45^{\circ}$ off of swath & $0.58 \mathrm{~K}$ & $0.60 \mathrm{~K}$ & $0.64 \mathrm{~K}$ \\
Perpendicular to swath & $0.47 \mathrm{~K}$ & $0.50 \mathrm{~K}$ & $0.54 \mathrm{~K}$ \\
\hline
\end{tabular}




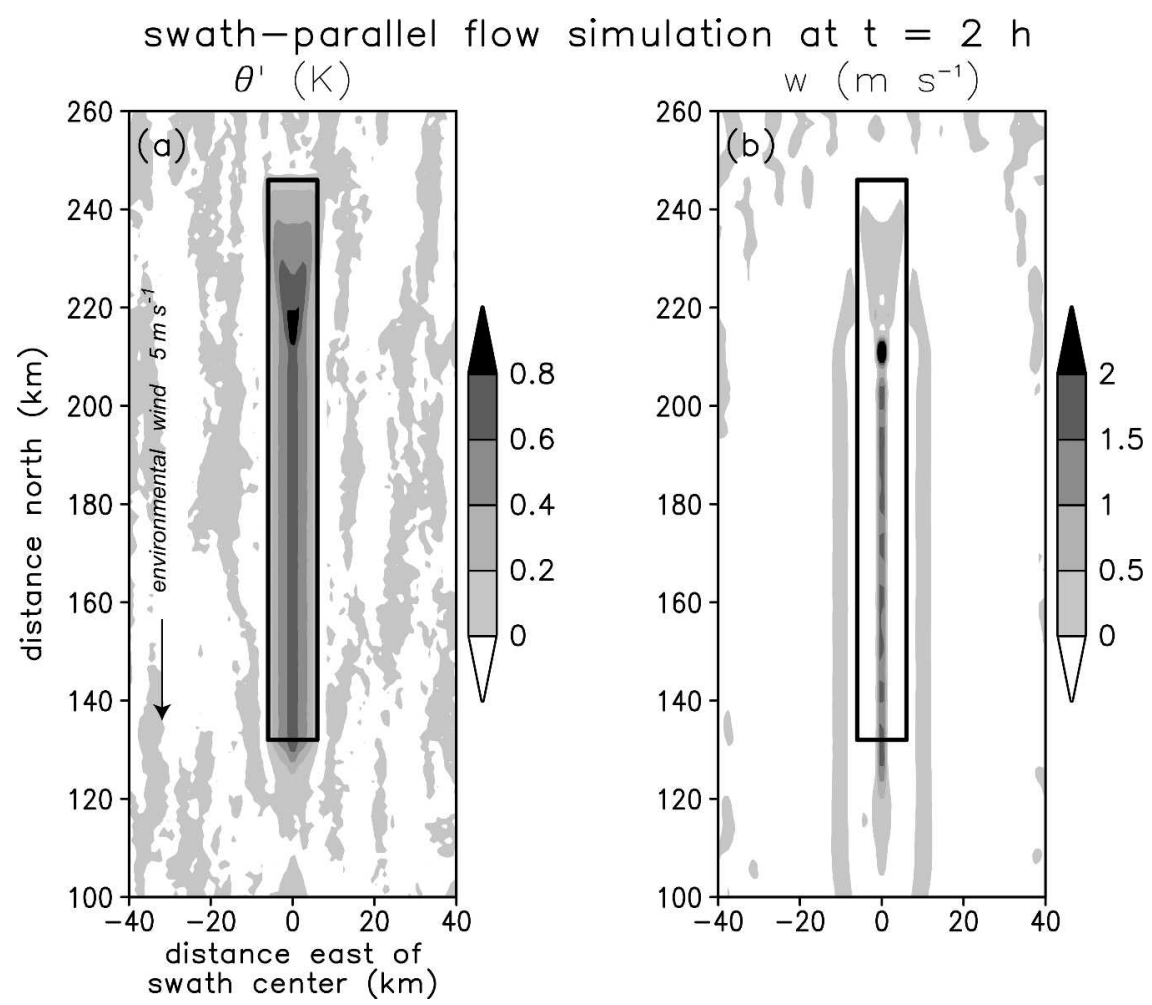

FIG. 12. Results from the experiment with along-swath flow of $5 \mathrm{~m} \mathrm{~s}^{-1}$ and no vertical wind shear, after $2 \mathrm{~h}$ of simulation: (a) potential temperature perturbation $(\mathrm{K})$ at $z=100 \mathrm{~m}$ AGL and (b) vertical velocity $\left(\mathrm{m} \mathrm{s}^{-1}\right)$ at $z=1100 \mathrm{~m} \mathrm{AGL}$. Both variables are shaded as shown, and the position of the simulated hailswath is outlined in black.

midafternoon evolution of cloudiness, not the rather lengthy process of diurnal destabilization that leads to this well-mixed boundary layer. The approach is relatively uncomplicated and allows us to focus on the present problem of convective development, rather than on the problems of diurnal boundary layer and soil evolution. The grid spacings for the experiment were hence chosen to resolve convective clouds (Table 1), not small-scale turbulent eddies in the boundary layer. ${ }^{6}$ To test the sensitivity of the simulations to flow direction (with respect to the swath), flow speed, and vertical wind shear, we utilized constant wind profiles and wind profiles with simple linear shear, incorporating a matrix of combinations of surface wind directions and deeplayer shear vectors that were parallel to the simulated swath, perpendicular to it, or at a $45^{\circ}$ angle to it.

In the control simulation, the soil was assumed to have a temperature and mixing ratio that were equivalent to the lowest atmospheric level (which would produce no surface fluxes); random noise of $-0.5 \mathrm{~K} \leq T_{\text {soil }}^{\prime}$

\footnotetext{
${ }^{6}$ Other numerical simulations of impacts of land surface heterogeneity upon regional weather have successfully used similar horizontal grid spacings, for example, Weaver and Avissar (2001; $\Delta=2 \mathrm{~km})$ and Adegoke et al. $(2003 ; \Delta=10 \mathrm{~km})$.
}

$\leq 0.5 \mathrm{~K}$ was then added to the soil temperature field, which led to heterogeneous background surface fluxes, and the development of realistic boundary layer cloud fields (e.g., cumulus cloud streets; not shown). For our experiments, we then introduced a simulated hailswath into the center of the domain, with the same width as the observed swath $(12.5 \mathrm{~km})$ and half its length $(115$ $\mathrm{km}$, chosen to permit a more economical domain size). This swath was characterized by a soil temperature that was $6 \mathrm{~K}$ higher than that of its surroundings. The 6-K perturbation roughly corresponds to the clear-day GOES infrared temperature measurements on the most prominent days and leads to simulated air temperature perturbations similar to those observed at 8D3. The swath also was characterized by a soil mixing ratio that was $1.5 \mathrm{~g} \mathrm{~kg}^{-1}$ lower than that of its surroundings, which was found to produce dewpoint temperature decreases over the swath comparable to those observed at $8 \mathrm{D} 3$ after the 4 July swath was created. Hence, in addition to the background random surface fluxes, the swath was characterized by an upward sensible heat flux and a downward latent heat flux. In time, these fluxes produced the observed symptoms of comparatively high air temperature and comparatively low dewpoint temperature over and downwind of the idealized hailswath. 
Air parcels passing over the swath acquire increased temperatures that are consistent with those observed at 8D3 (on the order of $1 \mathrm{~K}$ higher than the background; Table 2 and Fig. 12a). The zone of maximized low-level temperature generates a thermally direct solenoidal circulation (Fig. 12b), and in time the heated air can acquire its level of free convection (LFC). Within the control simulation, the random $0.5-\mathrm{K}$ soil temperature perturbations are not sufficient to induce convective initiation, regardless of wind direction, speed, and vertical shear. However, when the idealized pseudohailswath is added to the control simulation, under some circumstances deep convection occurs (Fig. 13; Table 2). The basic physical mechanism for convective initiation is relatively straightforward and is consistent with the prior studies on land surface inhomogeneities summarized above. Thus, in environments for which low-level air parcels have modest CIN (e.g., Fig. 11), the addition of a devegetated hailswath may facilitate the development of deep convection.

This result is sensitive to the lower-tropospheric flow direction. In particular, flow that is largely along the swath is much preferred for convective initiation (Table $2)$ : in this case air parcels spend a longer time over the warm ground, and the resulting plume of heated air is narrow and concentrated as opposed to broad and diffuse (cf. Figs. 12a and 14a). These factors, in turn, yield enhanced solenoidal circulations (cf. Figs. 12b and 14b). As well, in the case of along-swath flow, the vertical velocities are centered and within the swath (Fig. 12b), consistent with the findings of Hong et al. (1995) that, for narrow strips of heating, the thermally direct circulations that initially develop at the edges of the temperature discontinuity quickly combine into one consolidated cell. In contrast, in the case of across-swath flow the solenoidally generated ascending motions are spatially scattered because they follow the edges of the plume of heated air (Fig. 14b). Hence, the swathparallel low-level winds provide a more spatially coherent, long-lived region of upward motion, which again favors the initiation of deep convective clouds.

There is modest sensitivity to the surface wind speed: the model's surface bulk transfer scheme yields larger surface fluxes under stronger surface winds, but this is mitigated by parcels' decreased residence time over the swath, yielding comparable surface temperature perturbations (Table 2). Higher wind speeds produce longer plumes of heated air, but this does not necessarily aid in convective initiation, even though it implies a more widespread effect on regional temperatures. Hence, the key element in the simulations appears to be the direction of the low-level winds. The inclusion of vertical wind shear (we reran the Table 2 experiments with moderate shear values of $0.002 \mathrm{~s}^{-1}$, and a variety of shear orientations) did not significantly change the modeled low-level temperature perturbations for the simulations summarized in Table 2, nor the timing of convective initiation for the cases with along-swath

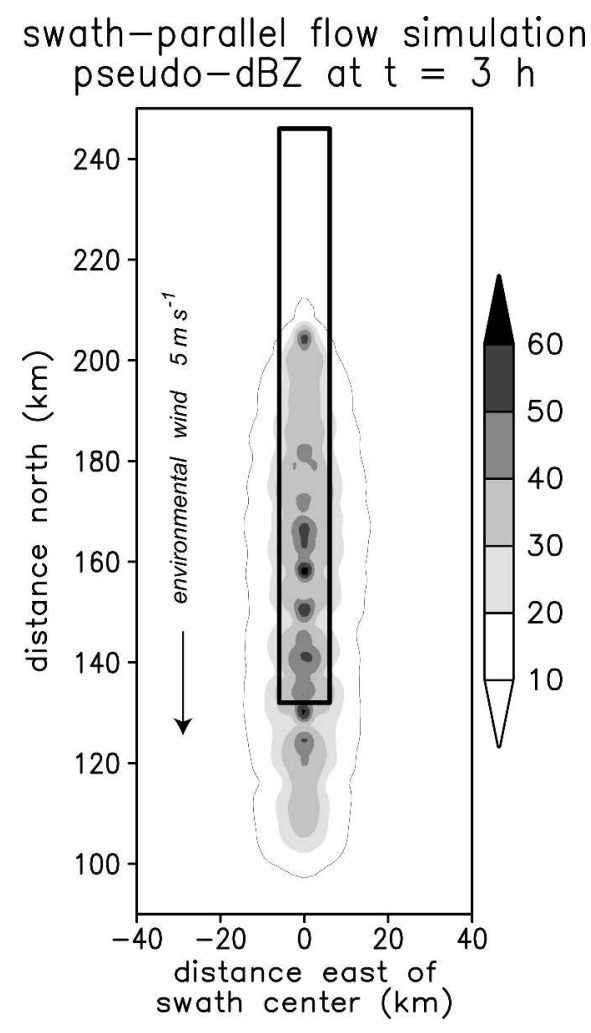

FIG. 13. The $0-10-\mathrm{km}-\mathrm{AGL}$ averaged radar reflectivity (dBZ, simulated) from the experiment with along-swath flow of $5 \mathrm{~m} \mathrm{~s}^{-1}$ and no vertical wind shear, after $3 \mathrm{~h}$ of simulation (i.e., $1 \mathrm{~h}$ later than Fig. 12). Reflectivity is shaded as shown, with the position of the simulated hailswath denoted by the thick box, and the extent of the convective cloudiness outlined by the thin contour.

flow. The primary differences in the simulations due to the addition of modest shear were that the convective storms became somewhat better organized and had different motion vectors (not shown).

To address what might happen should an active storm pass over a hailswath, we allowed a wellorganized storm from a higher shear experiment (along-swath surface flow of $5 \mathrm{~m} \mathrm{~s}^{-1}$ with along-swath shear of $0.003 \mathrm{~s}^{-1}$ ) to cross the north-south periodic boundary and reapproach the simulated hailswath. As the storm passed over the pseudo-swath after $5.25 \mathrm{~h}$ of simulation, its updrafts were enhanced (Fig. 15), in addition to which new updrafts also developed ahead of the surface outflow boundary (e.g., at $\mathrm{x}=+10 \mathrm{~km}$ in Fig. 15). The linear convective system extends well east and west of the $100 \mathrm{~km} \times 100 \mathrm{~km}$ region shown in Fig. 15 , and yet these pre-gust-front updrafts only developed in the vicinity of the swath, as shown. It therefore appears that the solenoidal circulations associated with hailswaths may be superimposed on those associated with the outflows of active storms, which may enhance their intensity or modify the locations at which new updrafts develop.

When we added a low-level stable layer to our ide- 


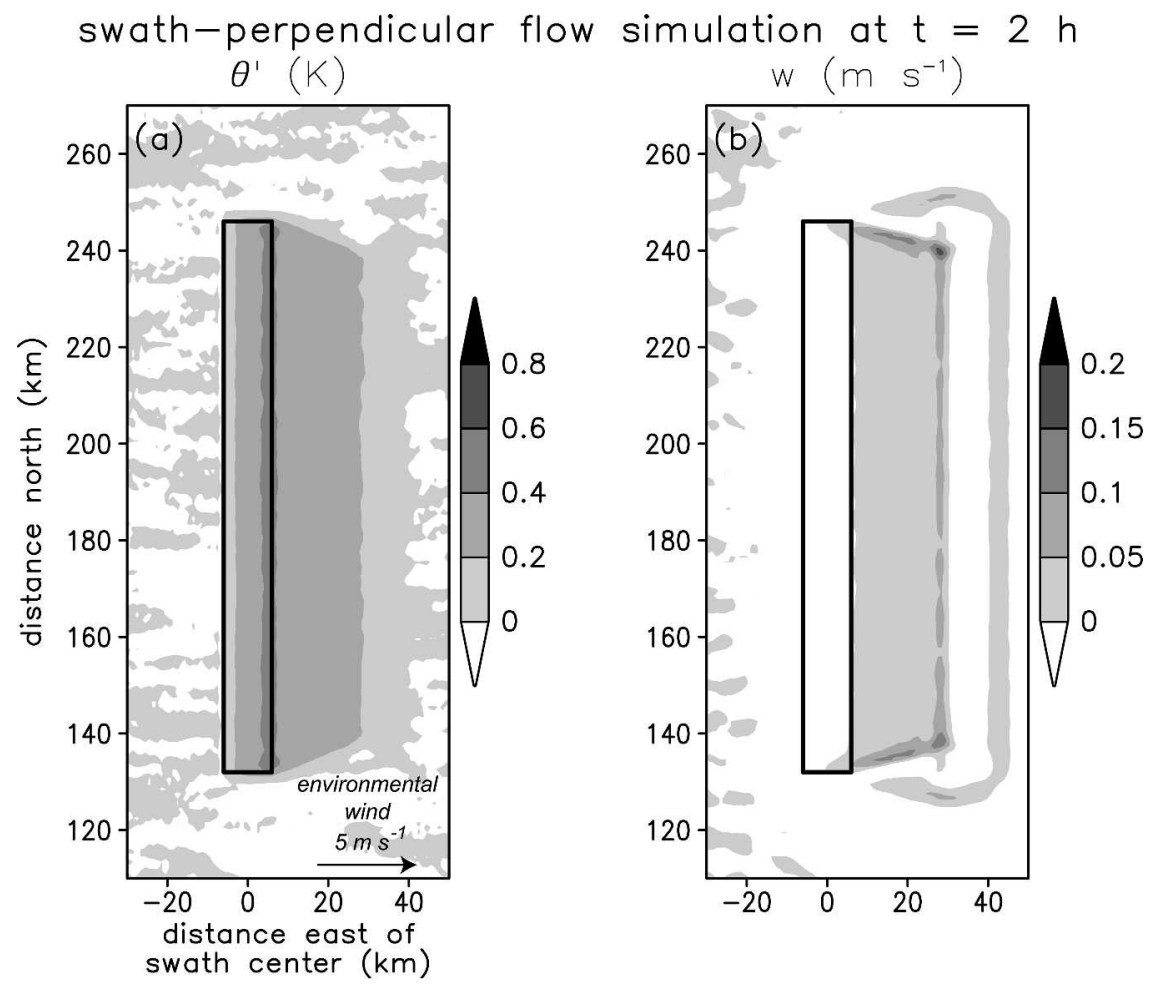

FIG. 14. Same as Fig. 12 except for the experiment with across-swath flow of $5 \mathrm{~m} \mathrm{~s}^{-1}$ and no vertical wind shear. Note that the scale for vertical velocity differs from that in Fig. 12.

alized simulations (Fig. 11), the impact of the pseudohailswath was less straightforward. Such an inversion might be expected to decouple the hailswath from the layer aloft in which elevated convection could develop. Although there is no straightforward initiation of deep convection in our stable layer simulations, the localized heating by the hailswath produces gravity waves within the stable layer, which in turn render ascent in the unstable layer lying above (Fig. 16a). The low-level heating also leads to ascent below the inversion, and to parcels that overshoot their equilibrium levels. As a result, the near-surface heating is accompanied by a quasi-steady cold anomaly farther aloft (above $300 \mathrm{~m}$ AGL in Fig. 16a). In turn, this cold anomaly near the top of the stable layer produces a buoyancy bore that lifts air as it propagates outward [e.g., in the manner described by Bretherton and Smolarkiewicz (1989)]. This buoyancy bore's speed is quite slow in the unstable layer above the inversion; therefore, much of its associated vertical motion is realized downstream of the swath, where advection by the background wind helps the bore to advance. As a result, in time the simulated values for upward velocity along and downstream of the swath in the elevated unstable layer exceeded 0.5 $\mathrm{m} \mathrm{s}^{-1}$ (Fig. 16b), and occasionally led to condensation, suggesting that the swath's impact may be nontrivial in some circumstances. The generation and modulation of real-world elevated convection is likely to be quite so- phisticated, and to rely at least partly on mesoscale features (e.g., isentropic ascent, presence of a low-level jet) that were beyond the reach of our current, idealized approach. Nevertheless it appears that, even when the low levels are stabilized, the inclusion of a hailswath can still impact an unstable environment aloft through the production of gravity waves within the stable layer.

Taken altogether, the above idealized simulations suggest that it is physically reasonable to expect hailswath devegetation to impact convective development in some situations, especially when there is modest CIN and the lower-tropospheric winds blow along the hailswath. When there is a thermal inversion and storms are elevated, things become more complicated to diagnose, but the impact of the idealized swath apparently is not negligible.

\section{b. Possible initiation/intensification of 17 July convective storm by 4 July devegetated hailswath}

During the early-morning hours of 17 July 2003, a diminishing area of light rain showers moved southeastward, approaching the 4 July devegetated hailswath by 1430 UTC. Between 1500 and 1515 UTC, two new cells developed upstream of the now-decayed showers, centered within the devegetated hailswath (Fig. 17); a new cumulonimbus turret was associated with the stronger, southeastern cell. The newly initiated cells moved along and remained centered within the swath over the next 


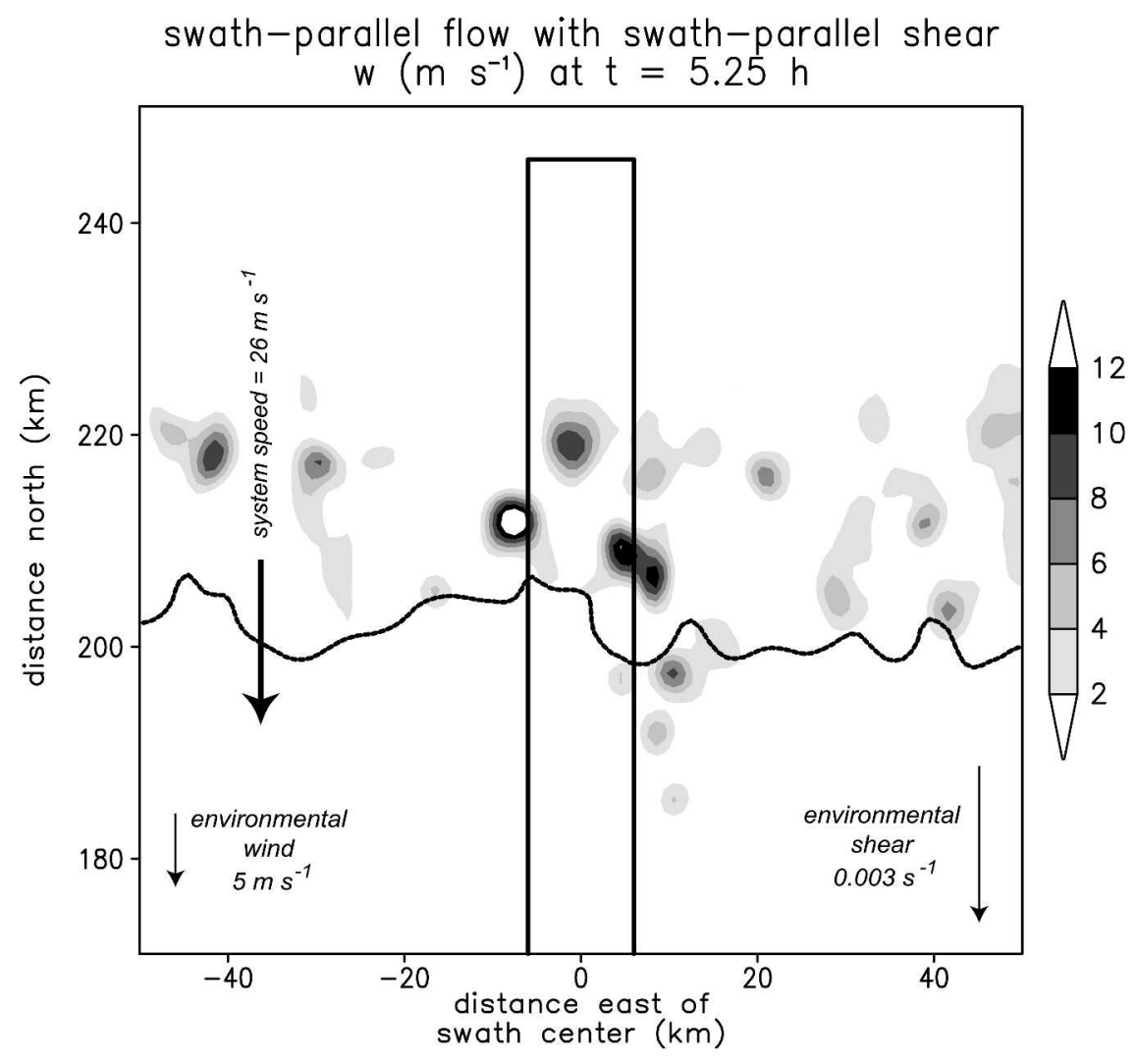

FIG. 15. The 0-10-km-AGL averaged vertical velocity $\left(\mathrm{m} \mathrm{s}^{-1}\right)$ from the experiment with along-swath flow of $5 \mathrm{~m} \mathrm{~s}^{-1}$ and along-line vertical wind shear of $0.003 \mathrm{~s}^{-1}$, after $5 \mathrm{~h} 15 \mathrm{~min}$ of simulation. Vertical velocity is shaded as shown, with the position of the simulated hailswath denoted by the thick box, and the extent of the surface cold pool outlined by the thick dashed contour (isopleth of $\theta^{\prime}=-2 \mathrm{~K}$ ). Note that the convective system has crossed the periodic domain and is now passing over the simulated hailswath for the second time.

hour and a half (Fig. 17), merging with one another around $1600 \mathrm{UTC}$, and with another storm around 1645 UTC.

The regional low-level winds varied, but were generally from the east; thus, flow was largely along the swath, a favorable arrangement according to our idealized simulations. Inspection of the 1200 UTC ABR and BIS soundings suggests that the storms were probably elevated, and that northwesterly flow aloft favored the storm's observed along-swath movement. Unfortunately, because of largely overcast skies, GOES infrared data did not reveal any surface temperature differences associated with the swath at this time, and the surface observations at Sisseton, South Dakota, were are also not very revealing because Sisseton was roughly $150 \mathrm{~km}$ away from the area of interest. Even so, the collocation of the convection's development and subsequent motion with the 4 July swath's position is conspicuous. This may be considered circumstantial evidence that the devegetated hailswath had some effect on convective development and intensity, presumably owing to dynamics similar to those discussed above.

\section{c. Possible effects of the 4 July devegetated hailswath upon 20 July storms}

As was noted briefly in section 3c, the 20 July 2003 hailstorms crossed the 4 July hailswath, leading to overlapping of the two swaths. The interaction of the 20 July 2003 storms with the 4 July swath further demonstrates its possible impacts upon deep convection. On 20 July, the line of developing storms was arrayed from northwest to southeast and moved toward approximately $140^{\circ}$ azimuth, such that the storms were nearly following one another and were on course to cross the 4 July hailswath at a $20^{\circ}-40^{\circ}$ angle (Figs. 7 and 18). At about 0800 UTC, the southeasternmost of these storms (outlined by thin black line in Fig. 18) began to interact with the 4 July devegetated hailswath. This first cell crossed the swath with little or no deviation in its motion (Fig. 18 ), nor in its intensity.

However, the second cell (shaded light gray in Fig. 18), which began to interact with the 4 July devegetated hailswath at around 0900 UTC, appeared to be significantly impacted by the swath. Between 0752 and 0902 UTC, the second storm moved with an average speed of 

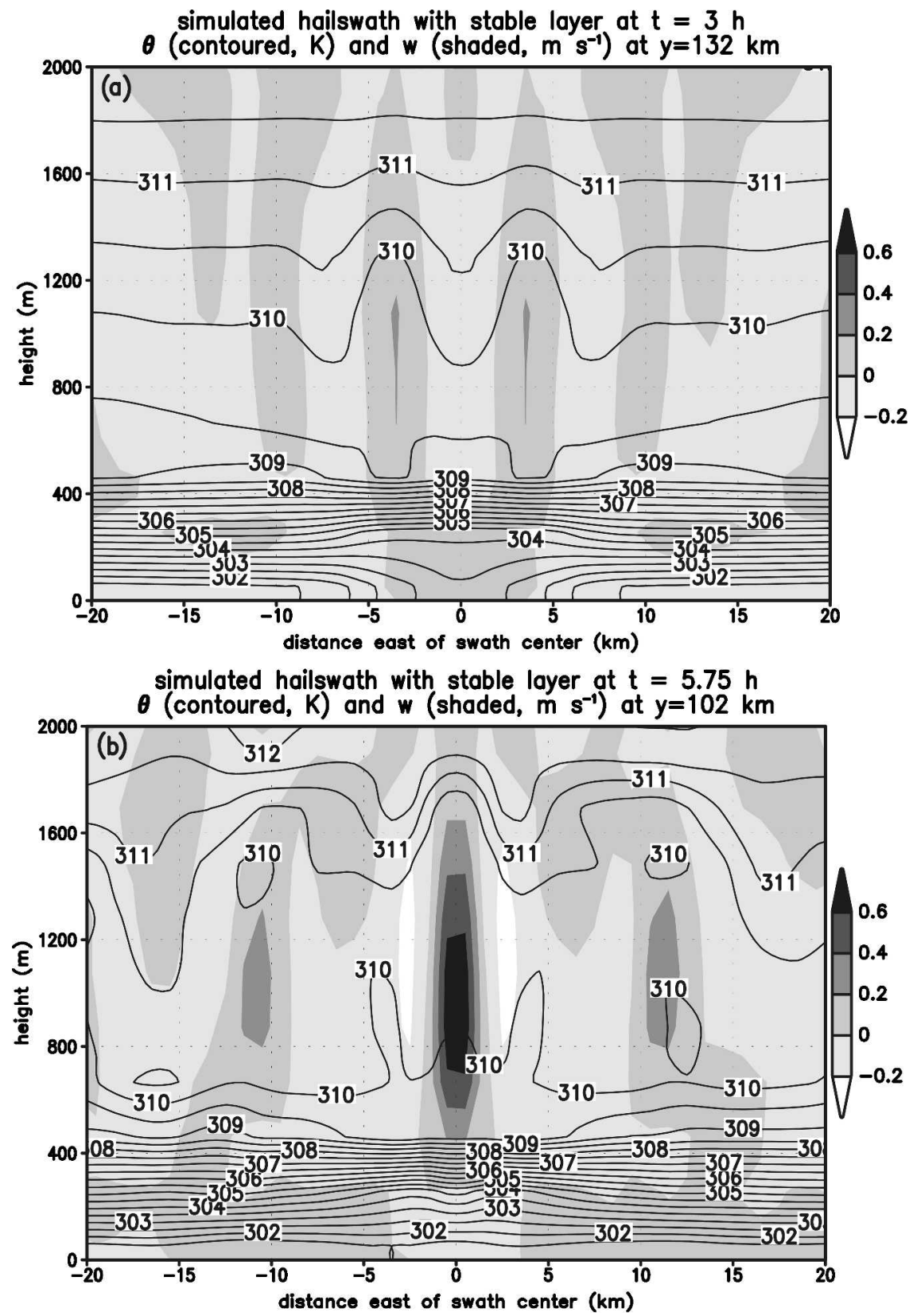

FIG. 16. Vertical cross sections of vertical velocity $\left(\mathrm{m} \mathrm{s}^{-1}\right.$, shaded as shown) and potential temperature (K, contoured) from the experiment with along-swath flow of $5 \mathrm{~m} \mathrm{~s}^{-1}$, no vertical wind shear, and stabilized lower troposphere (see Fig. 11): (a) after $3 \mathrm{~h}$ of simulation, with the cross section taken through $\mathrm{y}=132 \mathrm{~km}$ (the southern edge of the simulated hailswath), and (b) after $5 \mathrm{~h} 45 \mathrm{~min}$ of simulation, with cross section taken through y $=102 \mathrm{~km}(30 \mathrm{~km}$ south of the swath's southern edge).

$17.3 \mathrm{~m} \mathrm{~s}^{-1}$ toward $146^{\circ}$ azimuth. Then, between 0902 and 0952 UTC, when the storm was collocated with the swath, it moved with an average speed of $19.0 \mathrm{~m} \mathrm{~s}^{-1}$ toward $126^{\circ}$ azimuth. This change in direction $\left(20^{\circ}\right.$ to the left; cf. Fig. 18) is statistically significant at the 0.99 level ( $p=0.009$, corrected for serial autocorrelation) using a sampling interval of $5 \mathrm{~min}$ (the time required for each radar volume scan) for the above two periods. This new direction of motion was much more closely aligned with the 4 July hailswath, whose orientation in that location was roughly from $300^{\circ}$ toward $120^{\circ}$ azimuth. Following the base scan at 0952 UTC, the inflow region of the second cell began to pass into the break in the 4 July devegetation (discussed in section $3 \mathrm{~b}$ ), and at 


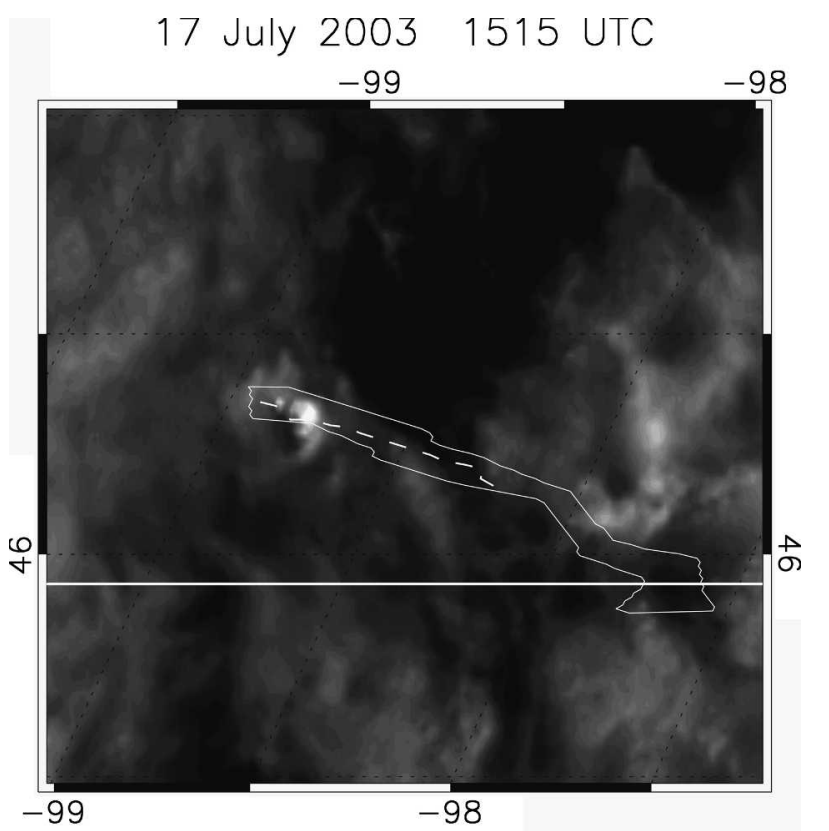$$
-99
$$

Albedo $(\%)$

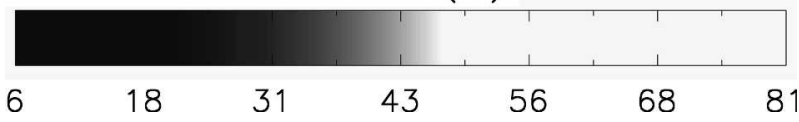

FIG. 17. GOES visible image from 1515 UTC 17 Jul 2003. The $4 \mathrm{Jul}$ hailswath and political boundaries are outlined for reference. The dashed line corresponds to the centroid of the predominant precipitation core from 1459 to 1633 UTC, as analyzed from Aberdeen, SD, radar data. The grayscale is condensed to emphasize the new convection over the swath.

this time it regained a more southward motion, moving toward $148^{\circ}$ over the next $15 \mathrm{~min}$, and with an average direction of $135^{\circ}$ azimuth through 1101 UTC. The second cell also began to move much more rapidly once it departed from the swath, averaging $28.4 \mathrm{~m} \mathrm{~s}^{-1}$ through 1101 UTC.

In addition, the second storm's reflectivity was decreasing through about 0845 UTC, but rebounded as it neared and passed over the hailswath; its reflectivity then decreased again as it neared the rear edge of the swath (Fig. 18, inset). Given the apparent ability of a pseudo-hailswath to impact convective development and vigor in our idealized simulations, it is therefore tempting to speculate that the 4 July swath also played some role in modifying the observed storm's intensity. However, the cause and effect relationship for the 20 July episode is not entirely clear.

The low-level winds near the swath were weak and generally from the east-southeast (Fig. 6a), again beneficially along the swath. Also, as on 17 July, regional soundings suggested that the storms were probably elevated. Because of the same problems as were mentioned in section 5b, GOES infrared and regional surface data did not reveal any surface temperature differences associated with the swath on this night. It is also
20 July 2003 convective echoes and 4 July 2003 hailswath

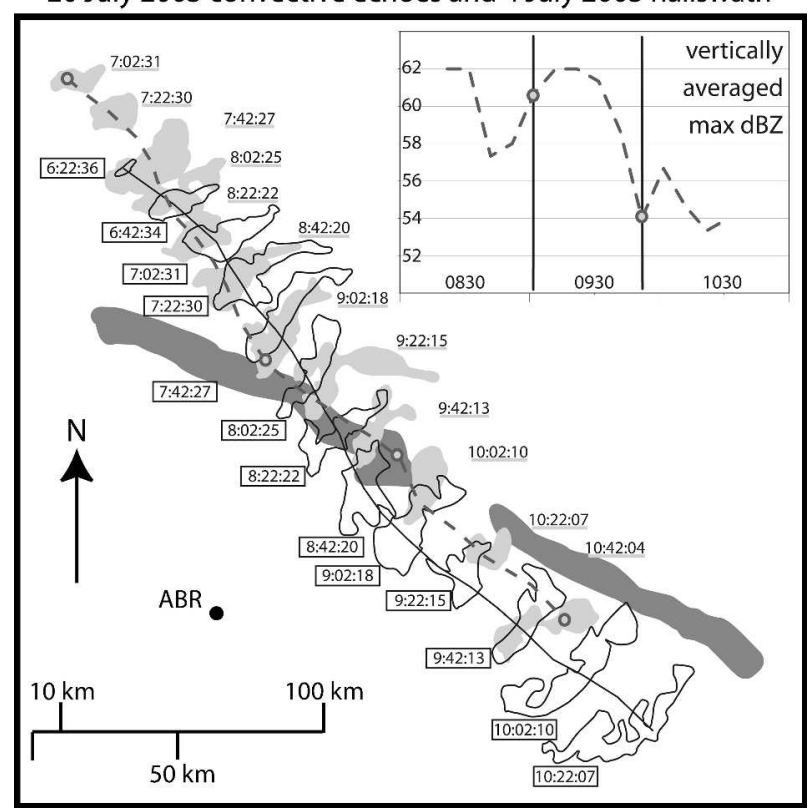

FIG. 18. Paths of the first and second storms on $20 \mathrm{Jul} 2003$ to cross the $4 \mathrm{Jul}$ devegetated hailswath's position. The $4 \mathrm{Jul}$ hailswath is shaded dark gray. The two storms are depicted by the outline of their $45-\mathrm{dBZ}$ contours every $20 \mathrm{~min}$, and by a track connecting their maximal reflectivity centroids every $10 \mathrm{~min}$. The first storm is outlined and tracked with a thin black line (outlined times in boxes). The second is shaded light gray and tracked by a heavy dashed line (outlined times underlined). The gray circles denote 0702, 0902, 0952, and 1042 UTC, the starting and ending times for the averages are discussed in the text. The upper-right corner summarizes the second storm's maximum reflectivity (average among 2, 4, and $8 \mathrm{~km}$ AGL) vs time, from 0822 to 1032 UTC.

unclear why the first cell that crossed the swath was not similarly deflected. The first storm appeared to be somewhat stronger than the second storm as it crossed the swath (not shown), which may imply that any perturbations associated with the swath did not influence it much.

Although Fig. 18 is but a crude summary of the Aberdeen radar data, it was evident from radar animations that the second cell moved along the devegetated hailswath for some time. Statistically, in comparison to the periods 0752-0902 and 0952-1101 UTC, the second cell had a significantly perturbed motion vector from 0902-0952 UTC: the differences in speed and direction among the three periods, corrected for serial autocorrelation, are significant at the 0.95 level (for speed, $p=$ 0.050 ; for direction, $p=0.002$ ). These statistical results reassure us that our subjective visual assessment of the animated radar data, in which it appears that the second cell tracks along the swath, are reasonable. This may be considered circumstantial evidence that the devegetated hailswath had some effect on the second cell, presumably owing to dynamics similar to those discussed earlier in this section. 


\section{Conclusions}

This paper documents the creation and structure of two devegetated hailswaths and their subsequent impacts on regional weather. On 4 July 2003, and again on 20 July 2003, thunderstorms crossed the Dakotas and produced long, narrow swaths of devastating crop damage that corresponded to reports of severe hail and wind. The observed swaths apparently occurred only where the systems' production of significant hail and strong winds coincided with a land cover that was particularly susceptible to damage. The devegetation caused changes in the surface reflectance that were readily discriminated through simple temporal differencing of MODIS NDVI images. The devegetated hailswaths measured approximately 1340 and $733 \mathrm{~km}^{2}$ in area, and persisted in imagery for over 6 weeks. These characteristics are in agreement with a broader study of devegetated hailswaths in the 1990s using NDVI image time series from the National Oceanic and Atmospheric Administration (NOAA) Advanced Very High Resolution Radiometer (Henebry and Ratcliffe 2003).

It is hypothesized that devegetated hailswaths can impact future convection via thermally direct circulations because, as in the 4 July 2003 case, they are elongated patches of maximized temperature owing to the locally enhanced Bowen ratio over dry devegetated ground. This basic interpretation is supported by idealized numerical simulations. Also, among episodes of cloudiness that were aligned with it, the 4 July hailswath appeared to play a part in the initiation and intensification of a convective storm on 17 July and in the temporarily deviant motion of a convective storm that crossed it on 20 July. As recent high-resolution field measurements from the International $\mathrm{H}_{2} \mathrm{O}$ Project (IHOP) have revealed, convective initiation is a complicated process that confounds short-term forecasters. Although the effects of devegetation and deforestation upon convective development have been treated by various studies, the similar impacts of hailswaths have received comparatively little study. Devegetated hailswaths are common to the central and northern plains during the summer months (Fig. 19; Henebry and Ratcliffe 2003), and as such an understanding of hailswaths may offer the possibility of improved short-term predictions, if their impacts can be understood.

It may be that, just as topography can provide enhanced predictability on the convective and mesoscales owing to its recurrent, well-understood effects upon atmospheric thermodynamics and kinematics, so too can forecast skill be gained by awareness of the existence of devegetated hailswaths and other kinds of large land surface disturbances, and by understanding the temporal and spatial scales on which they can impact convection. Because the cases studied in this paper relied upon somewhat coarse, conventional observations, it will be

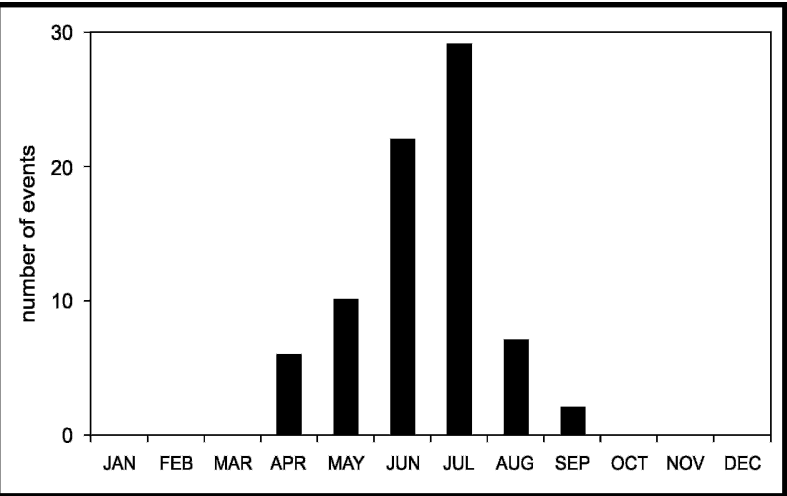

FIG. 19. Histogram of 76 hailswaths identified by Henebry and Ratcliffe (2003) in six northern plains states (Iowa, Kansas, Minnesota, Nebraska, North Dakota, and South Dakota) during 1990-99, distributed by month. These hailswaths were confirmed using the methods described in section $3 \mathrm{a}$.

useful in the future to make high-resolution observations of the temperature, humidity, and circulations associated with devegetated hailswaths. Additionally, more sophisticated numerical studies of hailswaths' possible dynamical impacts are being undertaken by other scientists, which may help to further elucidate the local processes associated with devegetated hailswaths and may provide a means of evaluating the realism with which operational mesoscale models can reproduce the observed effects of land-cover heterogeneities. Perhaps future studies of devegetated hailswaths can thereby unlock a small part of the problem of short-term predictability.

Acknowledgments. The authors gratefully acknowledge beneficial discussions with D. Loope and C. Rowe during the early stages of this effort. This research was supported in part by NSF Grant EIA-0131937 to GMH. MODIS imagery was acquired from the USGS EROS Data Center through the NebraskaView component of the AmericaView program. This paper is a contribution of the University of Nebraska Agricultural Research Division, Lincoln, Nebraska, Journal Series 14517.

\section{REFERENCES}

Adegoke, J. O., R. A. Pielke Sr., J. Eastman, R. Mahmood, and K. G. Hubbard, 2003: Impact of irrigation on midsummer surface fluxes and temperature under dry synoptic conditions: A regional atmospheric model study of the U.S. high plains. Mon. Wea. Rev., 131, 556-564.

Amburn, S. A., and P. L. Wolf, 1997: VIL density as a hail indicator. Wea. Forecasting, 12, 473-478.

Anthes, R. A., 1984: Enhancement of convective precipitation by mesoscale variations in vegetative covering in semiarid regions. J. Climate Appl. Meteor., 23, 541-554.

Avissar, R., 1992: Conceptual aspects of a statistical-dynamical approach to represent landscape subgrid-scale heterogeneities in atmospheric models. J. Geophys. Res., 97, 2729-2742. , and Y. Liu, 1996: Three-dimensional numerical study of 
shallow convective clouds and precipitation induced by land surface forcing. J. Geophys. Res., 101, 7499-7518.

Bentley, M. L., T. L. Mote, and P. Thebpanya, 2002: Using Landsat to identify thunderstorm damage in agricultural regions. Bull. Amer. Meteor. Soc., 83, 363-376.

Billet, J., M. DeLisi, B. G. Smith, and C. Gates, 1997: Use of regression techniques to predict hail size and the probability of large hail. Wea. Forecasting, 12, 154-164.

Bretherton, C. S., and P. K. Smolarkiewicz, 1989: Gravity waves, compensating subsidence and detrainment around cumulus clouds. J. Atmos. Sci., 46, 740-759.

Burgess, D. W., and L. R. Lemon, 1990: Severe thunderstorm detection by radar. Radar in Meteorology, D. Atlas, Ed., Amer. Meteor. Soc., 85-117.

Chang, J.-T., and P. J. Wetzel, 1991: Effects of spatial variations in soil moisture and vegetation on the evolution of a prestorm environment: A numerical case study. Mon. Wea. Rev., 119, 1368-1390.

Changnon, S. A., 1967: Areal-temporal variations of hail intensity in Illinois. J. Appl. Meteor., 6, 536-541.

—_, 1970: Hailstreaks. J. Atmos. Sci., 27, 109-125.

1971: Hailfall characteristics related to crop damage. $J$. Appl. Meteor., 10, 270-274.

_, 1977: The scales of hail. J. Appl. Meteor., 16, 626-648.

— aerial photography. J. Appl. Meteor., 10, 86-96.

— , and G. J. D. Hewings, 2001: Losses from weather extremes in the United States. Nat. Hazards Rev., 2, 113-123.

- , and J. Burroughs, 2003: The tristate hailstorm: The most costly on record. Mon. Wea. Rev., 131, 1734-1739.

Cutrim, E., D. W. Martin, and R. Rabin, 1995: Enhancement of cumulus clouds over deforested lands in Amazonia. Bull. Amer. Meteor. Soc., 76, 1801-1805.

DEM, cited 2003: Emergency management in North Dakota. North Dakota Division of Emergency Management. [Available online at http://www.state.nd.us/dem/reports/ sitrep2003.html.]

Doran, J. C., J. M. Hubbe, J. C. Liljegren, W. J. Shaw, G. J. Collatz, D. R. Cook, and R. L. Hart, 1998: A technique for determining the spatial and temporal distributions of surface fluxes of heat and moisture over the Southern Great Plains Cloud and Radiation Testbed. J. Geophys. Res., 103, 6109-6121.

Frisby, E. M., 1962: Relationship of ground hail damage patterns to features of the synoptic map in the upper Great Plains of the United States. J. Appl. Meteor., 1, 348-352.

_ 1963: Hailstorms of the upper Great Plains of the United States. J. Appl. Meteor., 2, 759-766.

Henebry, G. M., and I. C. Ratcliffe, 2003: Occurrence and persistence of hailstreaks in the vegetated land surface. Preprints, 17th Conf. on Hydrology, Long Beach, CA, Amer. Meteor. Soc., CD-ROM, JP5.3.

Homer, C., C. Huang, L. Yang, and B. Wylie, 2002: Development of a circa 2000 land cover database for the United States. Proc. 2002 ASPRS Annual Convention, Washington, DC, American Society for Photogrammetry and Remote Sensing, CD-ROM. [Available online at http://landcover.usgs.gov/pdf/ asprs_final.pdf.]

Hong, X., M. J. Leach, and S. Raman, 1995: A sensitivity study of convective cloud formation by vegetation forcing with different atmospheric conditions. J. Appl. Meteor., 34, 2008-2028.

Johns, R. H., and C. A. Doswell III, 1992: Severe local storms forecasting. Wea. Forecasting, 7, 588-612.

Klimowski, B. A., M. R. Hjelmfelt, M. J. Bunkers, D. Sedlacek, and L. R. Johnson, 1998: Hailstorm damage observed from the GOES-8 satellite: The 5-6 July 1996 Butte-Meade storm. Mon. Wea. Rev., 126, 831-834.

Knight, C. A., and N. C. Knight, 2001: Hailstorms. Severe Con- vective Storms, Meteor. Monogr., No. 50, Amer. Meteor. Soc., 223-254.

Lemon, L. R., 1980: Severe thunderstorm radar identification techniques and warning criteria. NOAA Tech. Memo. NWS NSSFC-3, $60 \mathrm{pp}$.

Lin, Y.-L., R. D. Farley, and H. D. Orville, 1983: Bulk parameterization of the snow field in a cloud model. J. Climate Appl. Meteor., 22, 1065-1092.

Mahfouf, J.-F., E. Richard, and P. Mascart, 1987: The influence of soil and vegetation on the development of mesoscale circulations. J. Climate Appl. Meteor., 26, 1483-1495.

Morgan, G. M., Jr., and N. G. Towery, 1976: On the role of strong winds in damage to crops by hail and its estimation with a simple instrument. J. Appl. Meteor., 15, 891-898.

Parker, M. D., and R. H. Johnson, 2004: Structures and dynamics of quasi-2D mesoscale convective systems. J. Atmos. Sci., 61, 545-567.

Peters, A. J., S. C. Griffin, A. Viña, and L. Ji, 2000: Use of remotely sensed data for assessing crop hail damage. Photogramm. Eng. Remote Sens., 66, 1349-1355.

Pielke, R. A., 2001: Influence of the spatial distribution of vegetation and soils on the prediction of cumulus convective rainfall. Rev. Geophys., 39, 151-177.

Rabin, R. M., S. Stadler, P. J. Wetzel, D. J. Stensrud, and M. Gregory, 1990: Observed effects of landscape variability on convective clouds. Bull. Amer. Meteor. Soc., 71, 272-280.

Rasmussen, E. N., and D. O. Blanchard, 1998: A baseline climatology of sounding-derived supercell and tornado forecast parameters. Wea. Forecasting, 13, 1148-1164.

Sánchez, J. L., R. Fraile, J. L. de la Madrid, M. T. de la Fuente, P. Rodriguez, and A. Castro, 1996: Crop damage: The hail size factor. J. Appl. Meteor., 35, 1535-1541.

Segal, M., R. Avissar, M. C. McCumber, and R. A. Pielke, 1988 Evaluation of vegetation effects on the generation and modification of mesoscale circulations. J. Atmos. Sci., 45, 2268-2292.

Tao, W.-K., and J. Simpson, 1993: Goddard Cumulus Ensemble Model. Part I: Model description. Terr. Atmos. Oceanic Sci., 4, 35-72.

Towery, N. G., G. M. Morgan Jr., and S. A. Changnon Jr., 1976: Examples of the wind factor in crop-hail damage. J. Appl. Meteor., 15, 1116-1119.

Weaver, C. P., and R. Avissar, 2001: Atmospheric disturbances caused by human modification of the landscape. Bull. Amer. Meteor. Soc., 82, 269-283.

Weisman, M. L., and J. B. Klemp, 1982: The dependence of numerically simulated convective storms on vertical wind shear and buoyancy. Mon. Wea. Rev., 110, 504-520.

Witt, A., M. D. Eilts, G. J. Stumpf, J. T. Johnson, E. DeWayne Mitchell, and K. W. Thomas, 1998: An enhanced hail detection algorithm for the WSR-88D. Wea. Forecasting, 13, 286-303.

Xue, M., K. K. Droegemeier, V. Wong, A. Shapiro, and K. Brewster, 1995: Advanced Regional Prediction System version 4.0 users guide. Center for the Analysis and Prediction of Storms, Norman, OK, 380 pp. [Available from ARPS Model Development Group, CAPS, University of Oklahoma, 100 East Boyd, Norman, OK 73019-0628.]

, — , and —, 2000: The Advanced Regional Prediction System (ARPS) - A multi-scale nonhydrostatic atmospheric simulation and prediction model. Part I: Model dynamics and verification. Meteor. Atmos. Phys., 75, 161-193.

-, and Coauthors, 2001: The Advanced Regional Prediction System (ARPS) - A multiscale nonhydrostatic atmospheric simulation and prediction tool. Part II: Model physics and applications. Meteor. Atmos. Phys., 76, 143-165.

Yan, H., and R. A. Anthes, 1988: The effect of variations in surface moisture on mesoscale circulations. Mon. Wea. Rev., 116, $192-208$ 